\title{
Meta-omics approaches to understand and improve wastewater treatment systems
}

\author{
Elisa Rodríguez $(\mathbb{D} \cdot$ Pedro A. García-Encina • \\ Alfons J. M. Stams • Farai Maphosa • \\ Diana Z. Sousa
}

Published online: 28 July 2015

(C) Springer Science+Business Media Dordrecht 2015

\begin{abstract}
Biological treatment of wastewaters depends on microbial processes, usually carried out by mixed microbial communities. Environmental and operational factors can affect microorganisms and/or impact microbial community function, and this has repercussion in bioreactor performance. Novel highthroughput molecular methods (metagenomics, metatranscriptomics, metaproteomics, metabolomics) are providing detailed knowledge on the microorganisms governing wastewater treatment systems and on their metabolic capabilities. The genomes of uncultured microbes with key roles in wastewater treatment plants (WWTP), such as the polyphosphate-accumulating microorganism "Candidatus Accumulibacter phosphatis", the nitrite oxidizer "Candidatus Nitrospira defluvii" or the anammox bacterium "Candidatus Kuenenia stuttgartiensis" are now available
\end{abstract}

Electronic supplementary material The online version of this article (doi:10.1007/s11157-015-9370-x) contains supplementary material, which is available to authorized users.

E. Rodríguez $(\bowtie) \cdot$ P. A. García-Encina

Department of Chemical Engineering and Environmental

Technology, Valladolid University, C/Dr. Mergelina s/n,

47011 Valladolid, Spain

e-mail: emrodriguezrodriguez@gmail.com

P. A. García-Encina

e-mail: pedro@iq.uva.es

E. Rodríguez

Socamex S.A., C/Cobalto 12, 47012 Valladolid, Spain through metagenomic studies. Metagenomics allows to genetically characterize full-scale WWTP and provides information on the lifestyles and physiology of key microorganisms for wastewater treatment. Integrating metagenomic data of microorganisms with metatranscriptomic, metaproteomic and metabolomic information provides a better understanding of the microbial responses to perturbations or environmental variations. Data integration may allow the creation of predictive behavior models of wastewater ecosystems, which could help in an improved exploitation of microbial processes. This review discusses the impact of meta-omic approaches on the understanding of wastewater treatment processes, and the implications of these methods for the optimization and design of wastewater treatment bioreactors.

Keywords Wastewater - Bioreactor · Metagenomics - Metatranscriptomics . Metaproteomics

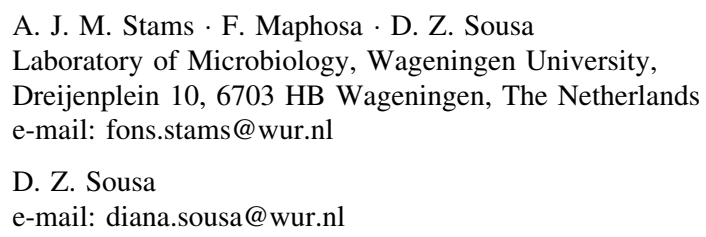

A. J. M. Stams

Centre of Biological Engineering, University of Minho, 4710-057 Braga, Portugal 


\section{Introduction}

Biological wastewater treatment relies on the great catabolic potential of microorganisms, which can transform or eliminate wastewater contaminants. Aerobic processes include those in which microbes use oxygen as electron acceptor for the oxidation of organic or inorganic substrates. Several aerobic reactor designs are currently applied, from the widely used activated sludge (AS) system to more advanced systems with improved sludge retention, such as membrane reactors, biofilm reactors and aerobic granular sludge reactors. In anaerobic processes, organic matter is mineralized to $\mathrm{CO}_{2}$ and methane in a reaction chain that comprises hydrolysis, acidogenesis, acetogenesis, and methanogenesis steps (Schink and Stams 2013). The upflow anaerobic sludge blanket (UASB) reactor, which was developed in The Netherlands in the late 1970s, is one of the most used anaerobic reactors for wastewater treatment. Other common anaerobic reactor types are the expanded granular sludge blanket (EGSB) reactor, the internal circulation (IC) reactor, the static granular bed reactor (SGBR) and anaerobic biofilm reactors. The combination of aerobic, anaerobic and anoxic processes allows removal of not only organic carbon compounds from wastewaters but also nitrogen and phosphate, which is of utmost importance because the release of these nutrients to the environment are main causers of eutrophication in surface waters.

The key to achieve a successful exploitation of biological wastewater treatment facilities lies in a thorough understanding of the microbial communities that catalyze the conversion of organic and inorganic compounds (Daims et al. 2006; He and McMahon 2011; Jenkins 2008). Cultivation methods can give important insights regarding the physiological properties of microorganisms involved in e.g. nitrification, denitrification, phosphorus removal, sulfate reduction, methanogenesis, xenobiotic remediation. Whole genome sequencing of bacterial and archaeal isolates has allowed to get information on functional genes and biochemical pathways of relevant wastewater treatment microorganisms (Supplementary Table 1). However, most microorganisms present in wastewater treatment systems are not thus far cultivated, either due to laboratorial biases or to interspecies metabolic dependence. The study of microbial communities as a whole, and their relation to process performance, represents nowadays a great challenge for bioengineers and microbiologists. Rapidly advancing techniques such as metagenomics (the study of all genes in a microbial community), metatranscriptomics (the study of gene expression in a microbial community), metaproteomics (the study of proteins from a microbial community), and metabolomics (metabolite profiling and analysis of metabolic fluxes) enable cultivation-independent analysis of a whole microbial community under specific environmental conditions (Handelsman et al. 1998) (Fig. 1). They offer the possibility to explore the genetic and physiological diversity of an ecosystem, generating information about the identity and potential metabolic capabilities of its microorganisms. Today, these innovative techniques constitute the key to study uncultured wastewater microbes and the metabolic pathways involved in the wastewater treatment processes, which is imperative for a better design, control and understanding of bioreactors. Furthermore, the integration of metaomics data through a systems microbiology approach can be used to construct mathematical models for predicting the response of environmental or engineered systems to external perturbations (Fig. 2).

This review highlights the potential of genomic and meta-omic approaches to understand the structure, function and interactions of microbial communities of wastewater treatment systems, and discusses how these genomic and meta-omics results influence the development and monitoring of these biotechnologies. Examples of relevant processes in presently used aerobic, anoxic and anaerobic wastewater systemsnamely, nitrogen removal (nitrification, denitrification, anammox), phosphorus removal (polyphosphate accumulation), sulfate reduction, syntrophic conversions, and methanogenesis-are used to explain the use and potential of genomics and meta-omics data on the understanding of biological wastewater treatment processes.

\section{Lessons learned from the genomes of wastewater treatment microbes}

Available genomes of wastewater treatment microbes have generated an excellent body of knowledge about their genomic and functional diversity. Comparative genomics can give new hints about genomic variability among functionally similar organisms. Genomic 


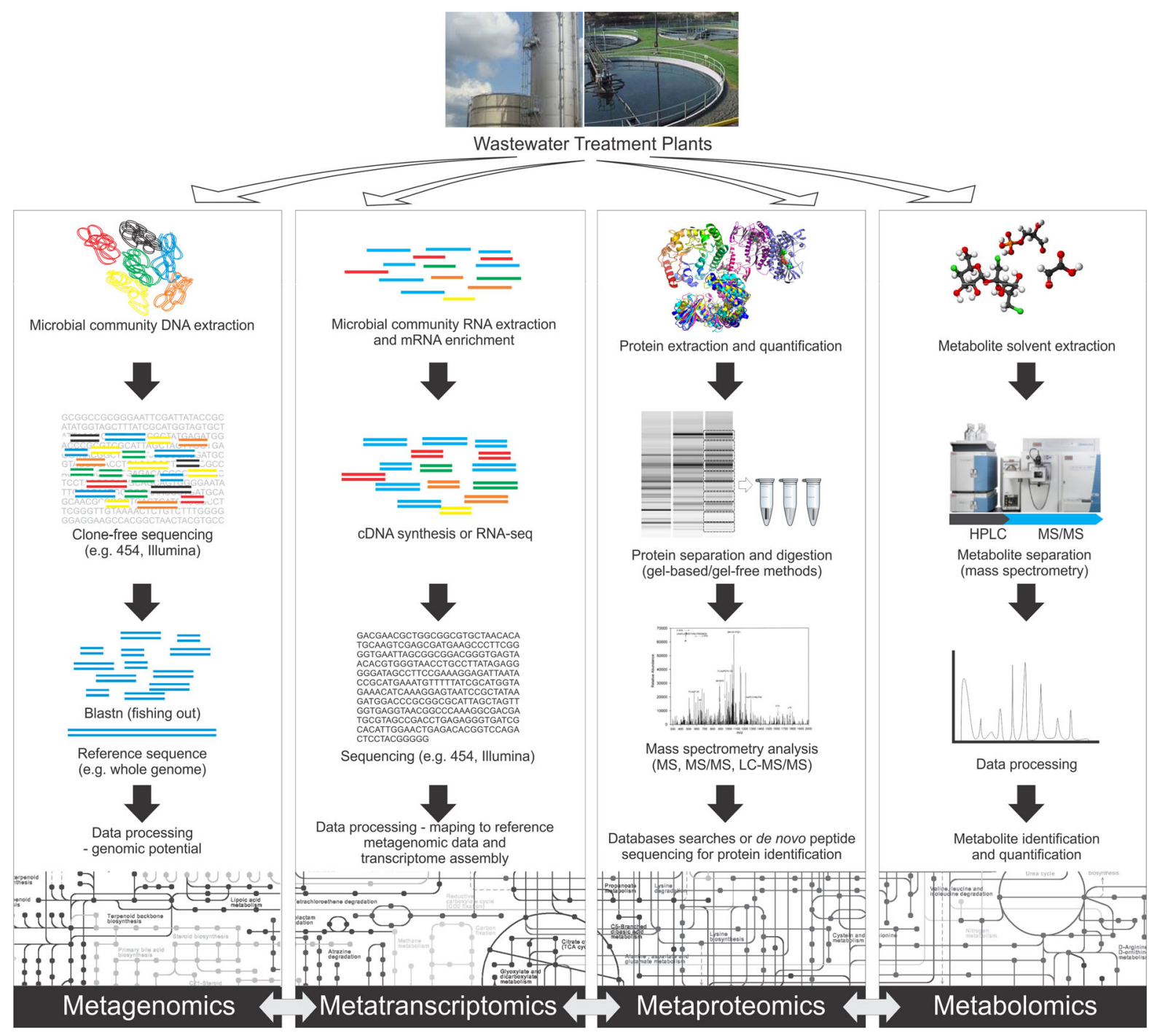

Fig. 1 An illustration with the main steps in metagenomic, metatranscriptomic, metaproteomic and metabolomic approaches

approaches are therefore important to increase our understanding of structure-function relationships in microbial communities and potentially leading to better knowledge about the stability of key processes in WWTP (Daims et al. 2006).

\subsection{Genomic adaptation to different environments in WWTP}

Genomic data help to understand the adaptive mechanisms to changing conditions of wastewater microbes, which is of key importance in WWTP, since different wastewater compositions and operational conditions might stimulate or inhibit the growth of specific microbes. Microorganisms need to adapt to different conditions and, at times, a more flexible metabolism results in competitive advantages.

The genomes of aerobic ammonia-oxidizing bacteria (AOB) have been extensively studied, and the presence of specific genes in some of the analyzed species may reveal adaptation to, for example, high concentration of ammonia as well as stress caused by ammonia starvation, high concentration of nitrogen oxides or even low concentrations of oxygen (Box 1). Another adaptation example is the type of nitrite oxidoreductase (NXR) (cytoplasmic or periplasmic) 


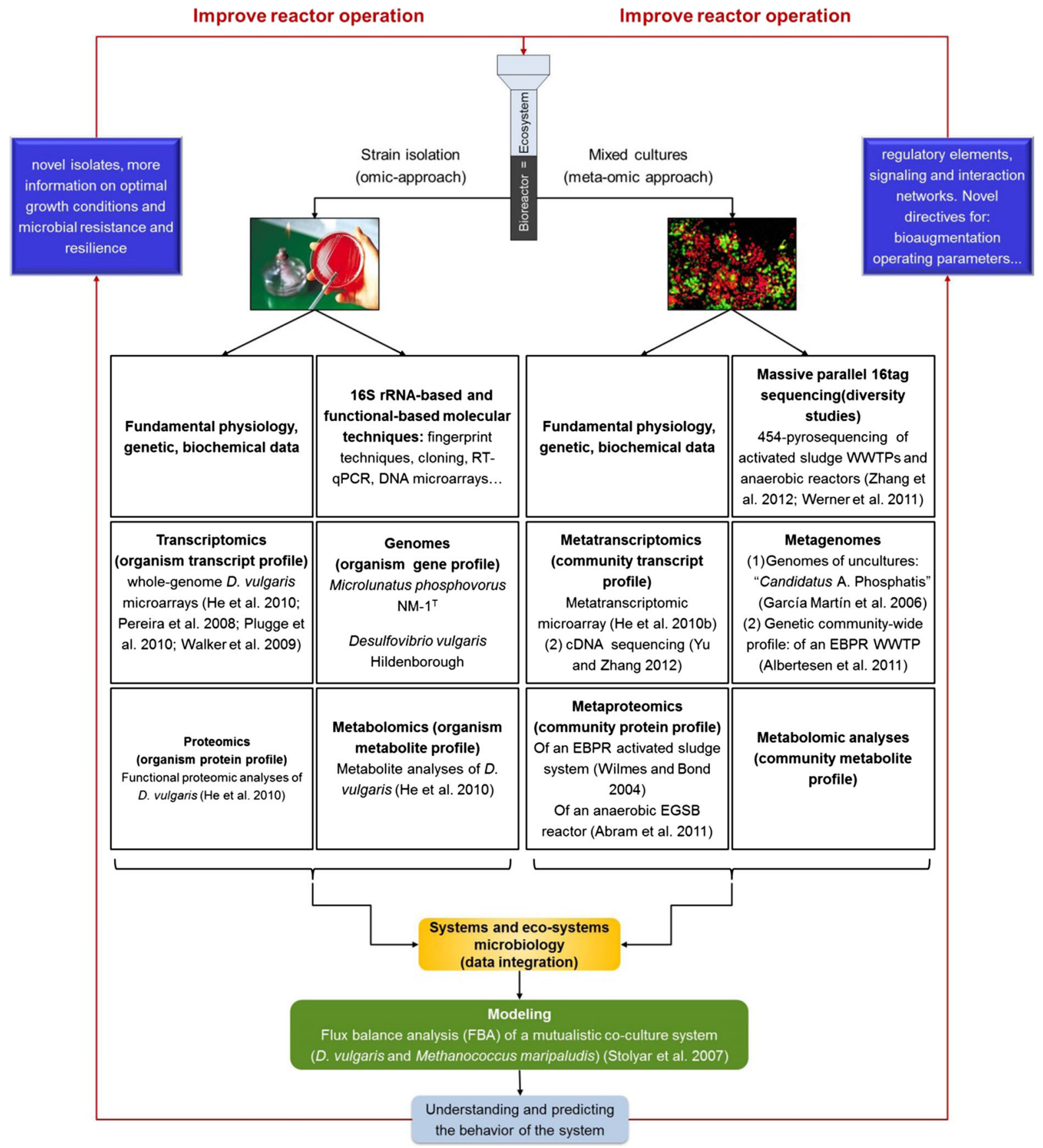

Fig. 2 Genomic and post-genomic approaches versus meta-omics approaches

present in nitrite-oxidizing bacteria (NOB). Species containing periplasmic forms of NXR are likely better adapted to low concentrations of nitrite (Box 2).

In denitrifying microbes (catalyzing nitrate reduction to dinitrogen gas) (Fig. 3) the presence of two different nitrate reductases-membrane-bound nitrate reductase (NAR) and periplasmic nitrate reductase (NAP) - may also reflect an ecophysiological adaptation to the environment they inhabit (Liu et al. 2013; Richardson 2000). In many of the best characterized 
Box 1 Genome analyses of ammonia-oxidizing bacteria (AOB)

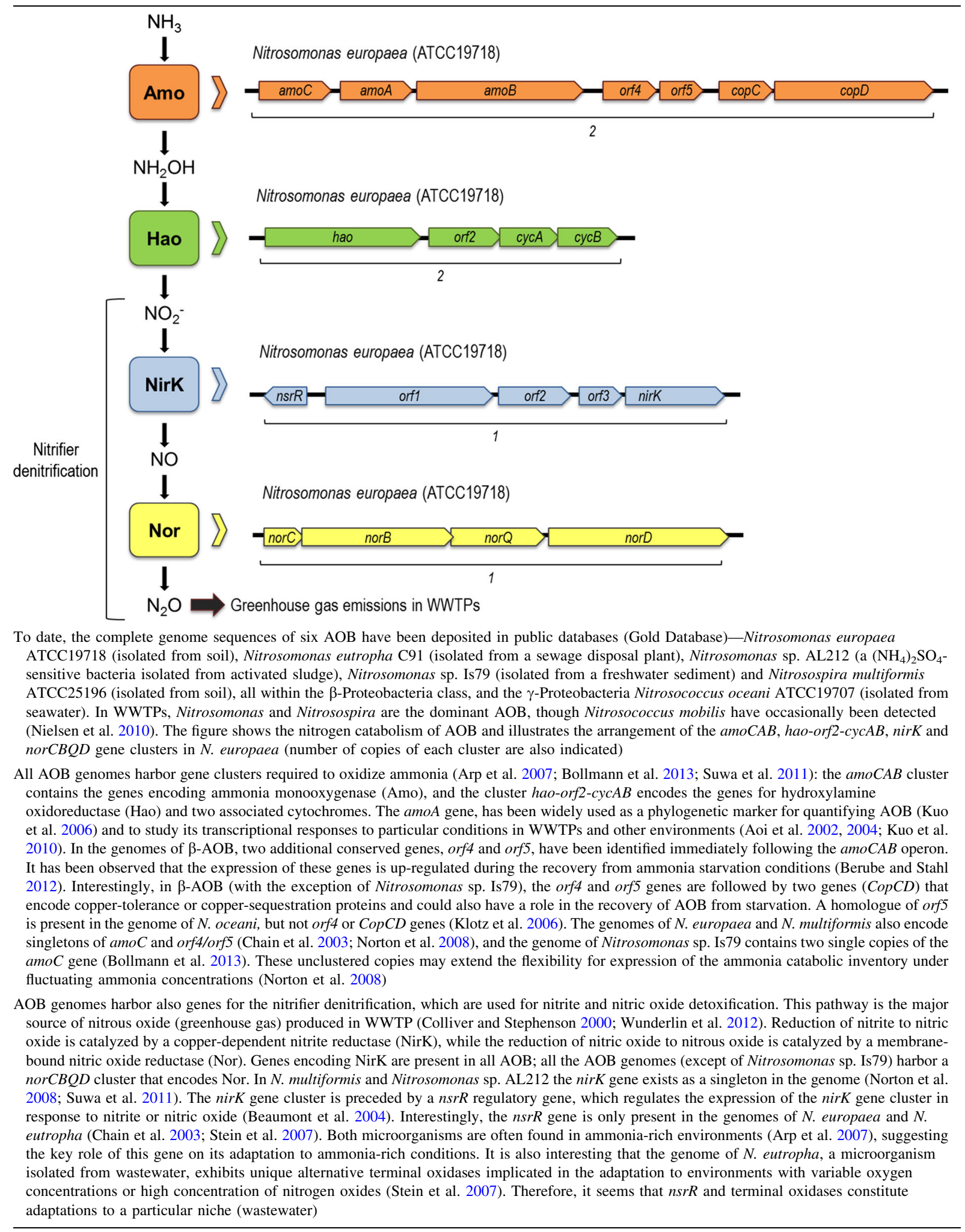


Box 2 Genome analyses of nitrite-oxidizing bacteria (NOB)

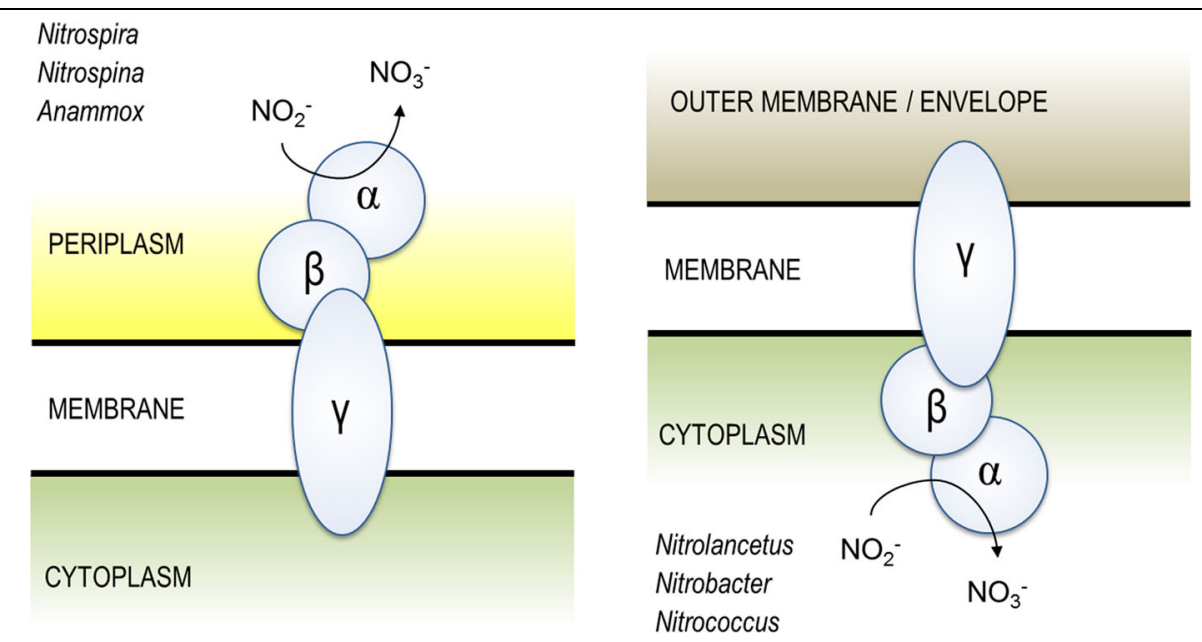

The available complete genomes of NOB include: Nitrobacter winogradsky Nb-225 (isolated from soil), Nitrobacter sp. Nb-311A (isolated from seawater), Nitrobacter hamburgensis X14 (isolated from soil), Nitrococcus mobilis Nb-231 (isolated from seawater) within the Proteobacteria phylum; Nitrolancetus hollandicus Lb (isolated from a nitrifying reactor) within the Chloroflexi, and Nitrospina Gracilis 3/211 (isolated from seawater) within the Nitrospinae phylum. The metagenome of "Candidatus Nitrospira defluvii" (obtained from an activated sludge enrichment culture) within the Nitrospirae phylum is also available (Lucker et al. 2010) (see the "Metagenomics" section of this review). Members of the genus Nitrospira are usually found as predominant NOB in WWTPs (Nielsen et al. 2010)

Genome-based information has revealed differences between NOB that should be considered to optimize control parameters (temperature, solids retention time, ammonia concentration, $\mathrm{pH}$...) in WWTPs exhibiting a nitrification process or to design bioaugmentation strategies when problems with nitrification arise. The genomes of all NOB harbor the enzyme NXR (nitrite oxidoreductase) (Lucker et al. 2013; Sorokin et al. 2012; Starkenburg et al. 2006); NXR is membrane associated and contains three subunits. The catalytic $\alpha$ subunit $(N x r A)$, the $\beta$ subunit $(N x r B)$, which probably channels electrons from the $\alpha$ - to the $\gamma$ subunit or directly to the membrane-integral electron transport chain (Kirstein and Bock 1993), and the putative $\gamma$ subunit $(N x r C)$ that channels electrons between the $\beta$-subunit and the electron transport chain (Lucker et al. 2010). In Nitrobacter, Nitrococcus and Nitrolancetus the NXR forms are closely related to each other and the $\alpha$-subunit NxrA, containing the substrate-binding site, is oriented toward the cytoplasmic side of the cytoplasmic membrane. On the contrary, Nitrospira, Nitrospina and Anammox bacteria possess a periplasmically oriented NXR which forms a distinct phylogenetic lineage (Lucker et al. 2010) (see figure). Periplasmic forms of NXR are thought to be more efficient, because more proton-motive force should be generated per oxidized nitrite and no nitrite/nitrate transport across the cytoplasmic membrane is needed. Accordingly, Nitrospira and Nitrospina are much better adapted to lower nitrite concentrations ( $k$-strategists) than most Nitrobacter,

Nitrococcus and Nitrolancetus ( $r$-strategists) (Sorokin et al. 2012). From this information, adjusting the sludge retention time and other parameters according to the wastewater characteristics in WWTPs seems of key importance to achieve satisfactory nitrification and thus avoid the formation of nitrous oxide gas

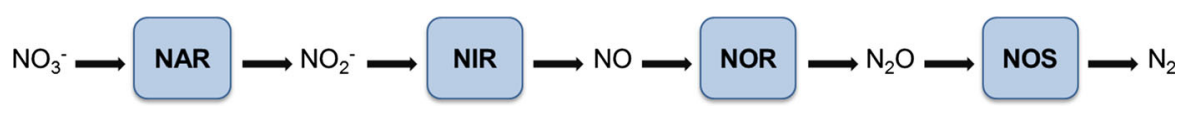

Fig. 3 Complete denitrification pathway and enzymes involved: nitrate reductase (NAR), nitrite reductase (NIR), nitric oxide reductase (NOR) and nitrous oxide reductase (NOS)

denitrification systems NAR catalyzes the anaerobic nitrate reduction to nitrite. However, NAP enzyme also supports anaerobic denitrification (Richardson 2000). Escherichia coli can express either NAR or NAP under anaerobic growth conditions. Competition experiments using strains expressing either NAR or
NAP, showed that under nitrate-limited conditions the strain expressing NAR was out-competed by the strain expressing NAP (Potter et al. 1999). This may reflect a low Ks (higher affinity) for nitrate when the NAP system is expressed (Richardson 2000). Despite this, NAP is less efficient in terms of energy coupling than 
NAR enzyme and therefore NAP enzyme might reflect an adaptation to nitrate-limited environments, where coupling efficiency would be sacrificed in favor of substrate affinity. A similar situation occurs in five different members of the genus Thauera isolated from wastewater, whose recently sequenced genomes (Liu et al. 2013) shows that Thauera sp. 27, Thauera sp. 28, Thauera linaloolentis 47Lol and Thauera sp. 63, reduce nitrate to nitrite by using NAP enzyme, while Thauera aminoaromatica S2 have the genetic information for NAR. These Thauera strains, also differ in their regulation of the denitrification process; whilst $T$. aminoaromatica accumulates negligible amounts of $\mathrm{NO}_{2}{ }^{-}$, the other strains reduce all $\mathrm{NO}_{3}{ }^{-}$to $\mathrm{NO}_{2}{ }^{-}$ before expressing nitrite reductase (NIR) and nitric oxide reductase (NOR). The transient accumulation of $\mathrm{N}_{2} \mathrm{O}$ is also different between the strains, ranging from 0.06 to $5 \%$ of all $\mathrm{NO}_{3}-\mathrm{N}$ finally reduced to $\mathrm{N}_{2}$ (Bakken et al. 2012). Incomplete denitrification can give rise to emission of $\mathrm{NO}$ and $\mathrm{N}_{2} \mathrm{O}$ (Schuster and Conrad 1992), a toxic compound for microorganisms and an important greenhouse gas, respectively. In microorganisms showing a complete denitrification pathway, as is the case of the five Thauera strains (Liu et al. 2013) and of the majority of cultured denitrifiers (Liu et al. 2013) including those isolated from wastewaters (Supplementary Table 1), emission of $\mathrm{NO}$ and $\mathrm{N}_{2} \mathrm{O}$ occurs when intermediates accumulate because the electron fluxes over the four subsequent denitrification steps are unbalanced. However, the exact regulation mechanism depends on the type of microorganism (Rodionov et al. 2005) and a large variation within taxonomic groups is observed (Bakken et al. 2012). The availability of more denitrifying genomes in combination with metatranscriptomic, proteomic and metabolomic and physiological studies will allow to gain better insight into the regulation of denitrification and thus may lead to the development of strategies to prevent $\mathrm{NO}$ and $\mathrm{N}_{2} \mathrm{O}$ emission in WWTPs.

Also regarding methanogens, genomic information gathered in recent years has highlighted their adaptation mechanisms to the environment. While Methanosarcinales use a partial oxidative tricarboxylic acid (TCA) cycle for anabolic $\mathrm{CO}_{2}$ assimilation, which results in the loss of one carbon as $\mathrm{CO}_{2}$, Class $\mathrm{I}$ methanogens and Methanomicrobiales use a partial reductive TCA cycle. The fact that using a partial reductive TCA cycle would preserve more fixed carbon could reflect the ability of hydrogrenotrophic methanogens to efficiently use low $\mathrm{H}_{2}$ concentrations, while Methanosarcinales are ubiquitous in environments with high acetate concentrations (Anderson et al. 2009b). In the recently sequenced genome of Methanoculleus bourgensis (Maus et al. 2012), genes encoding high affinity hydrogenases were found, indicating the adaptability of Methanomicrobiales to low $\mathrm{H}_{2}$ concentrations. Functional-gene arrays, proteomic and metabolite analyses in model hydrogenotrophic methanogens have been used to reveal mechanisms of regulation and global patterns of gene expression of this archaea under different growth conditions, such as $\mathrm{H}_{2}$ limitation (Hendrickson et al. 2007; Walker et al. 2012; Xia et al. 2009). Different responses of homologous genes, such as those encoding for hydrogenases ( $h m d$, hmdII) enable methanogens to adapt to changes in substrate availability.

It is has been observed that larger genomes are generally associated with wide metabolic versatility versus smaller genomes. For example Methanosarcinales (genome size between 1.9 and $5.7 \mathrm{Mb}$ ) (Genomes Online Database) are metabolically versatile, as compared to hydrogenotrophic methanogens which have smaller genomes (between 1.2 and $2.9 \mathrm{Mb}$ for Methanococcales, Methanobacteriales, and Methanopyrales, and between 1.5 and $3.5 \mathrm{Mb}$ for Methanomicrobiales and Methanocellales) (Genomes Online Database), and have a more restricted metabolism. The large differences observed in the genome sizes of Methanosarcinales reflect the observed diversity in phenotypic properties, e.g. Methanosaeta thermophila, which possesses the smallest genome within Methanosarcinales (1.9 Mb) is an obligate aceticlastic methanogen, while Methanosarcina acetivorans, which exhibit the largest genome $(5.7 \mathrm{Mb})$, is a metabolically diverse methanogen able to use acetate, methanol, methylamine, dimethylamine, and trimethylamine, and likely other one-carbon compounds as the analysis of its genome suggested (Galagan et al. 2002; Sowers et al. 1984). In the case of syntrophic microorganisms, syntrophic specialists seem to have smaller genomes (e.g. Syntrophus aciditrophicus SB, $3.18 \mathrm{Mb}$; Syntrophomonas wolfei DSM2245B, $2.94 \mathrm{Mb}$; Pelotomaculum thermopropionicum SI, $3.02 \mathrm{Mb}$ ) than those that have a more versatile metabolism (e.g. Syntrophobacter fumaroxidans MPOB, $4.99 \mathrm{Mb}$; Desulfatibacillum alkenivornas AK01, $6.52 \mathrm{Mb}$; 
Desulfovibrio alaskensis G20, 3.73 Mb) (Supplementary Table 1).

\subsection{Ecological roles of phosphate accumulating organisms (PAOs) in denitrification and production of storage compounds}

Available genomes of PAOs have confirmed their ability to denitrify. In 'Candidatus Accumulibacter phosphatis', which is primarily responsible for enhanced biological phosphorous removal (EBPR) in laboratory- and full-scale plants (He and McMahon 2011), nitrate reductase appears to be absent, but the genome does encode the rest of the denitrification pathway from nitrite onwards. It has been suggested that flanking EBPR species must perform nitrate reduction, thus supplying the dominant $A$. phosphatis population with nitrite for respiration (Martin et al. 2006).

Besides Accumulibacter, members of Actinobacteria [Microlunatus phosphovorus NM-1, Tetrasphaera australiensis, T. elongata, T. japonica, T. jenkinsii (Kawakoshi et al. 2012; Kristiansen et al. 2013; Supplementary Table 1)] have been identified as important PAOs in some EBPR systems (Seviour et al. 2008), and also these contain genes involved in denitrification. The NirK gene, which codes for a nitrite reductase, has been detected in the Tetrasphaera genomes, however sets of genes allowing complete denitrification have not been found (Kawakoshi et al. 2012; Kristiansen et al. 2013).

The genomes of Actinobacterial PAOs show that, as opposed to Accumulibacter, the Actinobacterial PAO M. phophovorus lacks the phaABC genes for polyhydroxyalkanoates (PHA) synthesis (Kawakoshi et al. 2012), suggesting their inability to synthesize PHAs anaerobically. Notwithstanding, M. phosphovorus microorganisms could produce PHA under aerobic conditions, since they have homologues of the $y f c \mathrm{YX}$ and phaJ gene clusters of $E$. coli and $P$. putida, respectively, which are involved in the $\beta$ oxidation pathway for PHA synthesis. In all four Tetrasphaera genomes analyzed by Kristiansen et al. (2013), candidate genes for both acetyl-CoA acetyltransferase $(p h a A)$ and acetoacetyl-CoA reductase $(p h a B)$ were identified, but PHA synthase ( $p h a C)$ was only found in the $T$. japonica genome, suggesting that only $T$. japonica have the potential to synthesize PHAs. However, according to the constructed metabolic model for Tetrasphaera (Kristiansen et al. 2013), these Actinobacterial PAOs can grow and ferment glucose and produce glycogen under anaerobic conditions. Under aerobic conditions, the stored glycogen is degraded to provide carbon and energy for growth and polyphosphate formation. Likewise, as opposed to Accumulibacter, the Actinobacterial PAOs possesses the genes for the assimilation of glucose (Martin et al. 2006; Kawakoshi et al. 2012; Kristiansen et al. 2013). Details into the physiology inferred and/or confirmed through genomic studies and on the range of substrates available for the different PAO are of key importance to understand the competition between PAOs, and between PAOs and other potential competitors such as the glycogen-accumulating organisms (GAOs) in EBPR WWTPs if this biotechnological process is to be operated more efficiently.

\subsection{Clues for the avoidance and control of activated sludge bulking and foaming}

Bulking and foaming are especially common problems related to solids separation in WWTP, and high operating costs are invested to combat it. "Candidatus Microthrix parvicella" is one of the most common filamentous organisms in WWTP, and it is commonly associated to these bulking or foaming events. The genomes of two strains of these versatile microorganisms (RN1 strain and Bio17-1 strain) are now available (McIlroy et al. 2013; Muller et al. 2012) and a metabolic model of the RN1 strain has been developed that proportionate interesting clues for developing control strategies for this filamentous bacterium.

The $M$. parvicella RN1 genome contains putative genes for the $\beta$-oxidation of long chain fatty acids (LCFAs) to generate acetyl-CoA, and putative exocellular triacylglycerol (TAG) lipase encoding genes for hydrolysis of lipids to their constituent LCFA and glycerol moieties, which is consistent with its previously observed strong preference for lipids as carbon source (McIlroy et al. 2013). Under anaerobic conditions, the metabolic model proposes that these LCFA are used to synthesize triacylgycerol (TAG), which is used for carbon storage. This storage compound is functionally analogous to PHA in Accumulibacter, thus providing the energy and intermediates required for $M$. parvicella growth under aerobic conditions. Genome data also suggests that in strain RN1, trehalose is functionally analogous to glycogen in 
Accumuibacter. Thus, trehalose would be utilized anaerobically, and then their replenishment would occur aerobically.

Both strains are able to accumulate phosphate, while as opposed to Accumulibacter in which polyphosphate serves as an anaerobic energy reserve for carbon uptake, the presence of genes encoding a polyphosphate glucokinase and a polyphosphate/ATP NAD+ kinase in $M$. parvicella RN1 suggests the role for polyphosphate in direct phosphorylation of intermediates involved in energy metabolism. The genome sequence data also suggest that nitrate in both strains and nitrate and/or nitrite in RN1 strain, may substitute for oxygen as the terminal electron acceptor for anaerobic respiration, although only nitrate reduction ability is supported by experimental evidence.

Strategies or methods developed to control this undesirable microorganism are actually based in changing operational conditions or dosing with polyaluminium chloride (PAX-14). Sludge retention time control is limited by the need to maintain a SRT that favors other process in the wastewater treatment plant, such as nitrification. The rapid uptake rate and storage of LCFA in M. parvicella also limits other control measures, such as trying to eliminate source food. Hence, the genetic inventory of "Candidatus Microthrix parvicella" makes it of particular interest for future better and more specific control strategies.

\subsection{Electron flow in sulfate-reducing bacteria (SRB) Interspecies electron transfer during syntrophic growth}

In general, SRB possess large genomes (Zhou et al. 2011), which likely reflects their versatility concerning carbon and energy metabolism. Nevertheless, a large variation in genome sizes and in gene repertories is observed among major SRB groups and even between species and strains of the same genus. Comparative analyses of SRB genomes have clarified their mechanisms for energy conservation linked to sulfate reduction (Keller et al. 2014; Pereira et al. 2011), though still several important mechanisms remain to be elucidated further. As an example of the great insight provided by genomics studies, one can refer to the occurrence of the hydrogen-cycling model, first proposed by Odom and Peck (1981) to explain growth of Desulfovibrio vulgaris on lactate and sulfate. According to this model, electrons and protons generating from the oxidation of organic acids serve as substrate for a cytoplasmic hydrogenase. The resulting $\mathrm{H}_{2}$ could diffuse through the cytoplasmic membrane to be reoxidized by periplasmic hydrogenases. Electrons produced from $\mathrm{H}_{2}$ oxidation would be delivered to a $c$ type cytochrome pool for returning to the cytoplasm through transmembrane protein complexes and used for sulfate reduction. The protons released would contribute to the chemiosmotic potential. Genomic studies have shown that this mechanism is important only for some microorganisms and not for others, such is the case of Clostridia (Keller and Wall 2011; Pereira et al. 2011; Ramos et al. 2012). SRB belonging to Clostridia practically lack cytochromes $c$ or associated membrane complexes to deliver electrons from periplasmic hydrogenases to terminal reductases (Pereira et al. 2011), indicating that periplasmic electron transfer pathways are not important in these bacteria for the delivery of electrons to the sulfate reduction pathway. On the contrary, the large number of cytochrome $c$ and cytochrome $c$-associated membrane redox complexes observed in $\gamma$-Proteobacteria suggests that the hydrogen-cycling model may be of importance in the bioenergetics of this group. The large number of cytochromes $c$ has been correlated with increased respiratory versatility in anaerobes (Thomas et al. 2009), suggesting that $\gamma$-Proteobacteria occupy environments with variable redox and substrate conditions, such as the wastewater environment.

Alternative strategies for energy conservation in SRB include electron bifurcation and electron configuration mechanisms. A number of cytoplasmic [NiFe] and $[\mathrm{FeFe}]$ hydrogenases, formate dehydrogenases (FDH), and heterodisulfide reductase-related proteins detected in SRB genomes are likely candidates to be involved in energy coupling through electron bifurcation, from diverse electron donors such as $\mathrm{H}_{2}$, formate, pyruvate, $\mathrm{NAD}(\mathrm{P}) \mathrm{H}, \beta$-oxidation (Pereira et al. 2011). In Desulfovibrio spp. the transmembrane complex QmoABC participates in a configuration of electrons to APS reductase for bisulfite production (Ramos et al. 2012). Desulfovibrio alaskensis G20 which lacks cytoplasmic hydrogenases necessary for the hydrogen-cycling model (Hauser et al. 2011), likely employs a model of electron flow from lactate by configuration of electrons to adenosine phosphosulfate (APS) for sulfite production (Keller et al. 2014). With the availability of complete genome sequences for a number of SRB, electron carriers and bioenergetic 
pathways can be elucidated in more detail, which is of importance to understand why certain SRB species prevail in a particular wastewater environment.

\subsection{Interspecies electron transfer during syntrophic growth}

Syntrophic interactions constitute an essential process in the anaerobic treatment of wastewaters for the complete mineralization of central intermediates, such as propionate and butyrate. Syntrophs can be metabolic specialists restricted to syntrophic metabolism (e.g. Syntrophomonas species), or they can also grow in the absence of hydrogen-utilizing partner by using inorganic electron acceptors, such as sulfate (e.g. Syntrophobacter species, Desulfovibrio vulgaris Hildenborough, some Pelotomaculum species). These last (non-specialists) can display the syntrophic or the sulfidogenic metabolism depending on the imposed environmental conditions. The presence of multiple formate dehydrogenase and hydrogenase genes in the genomes of syntrophs (Pelotomaculum thermopropionicum, Syntrophobacter fumaroxidans) have shown that syntrophic metabolism involves not only hydrogen but also formate transfer in methanogenic environments (Plugge et al. 2012; Sieber et al. 2012). The availability of genomes of syntrophic bacteria have allowed to get more insight into the importance of formate as interspecies electron carrier in syntrophic communities: a systematic functional profiling of the genomes of syntrophic versus non-syntrophic anaerobic fatty acid degrading bacteria have revealed the differences that make that a short chain fatty acid degrading bacteria are able to grow in syntrophy with methanogens and another not. Extra-cytoplasmic formate dehydrogenases and formate transporter are absent in genomes of non-syntrophs, whereas they are present in a number of syntrophs. This indicates that extracytoplasmic formate production is essential for syntrophic propionate and butyrate oxidation, two important intermediates in the anaerobic degradation process (Worm et al. 2014).

\subsection{Unravelling phylogenetic differences among methanogens}

Complete genome sequences of ten methanogenic archaea previously isolated from anaerobic sludge are now available, and include the orders
Methanosarcinales (four genomes), Methanomicrobiales (three genomes) and Methanobacteriales (four genomes) (Supplementary Table 1). Genomics has helped to unravel phylogenetic relationships among methanogens. Based on enzyme and co-factors involved in methanogenesis, methanogens were phylogenetically divided into two classes; Class I comprises Methanococcales, Methanobacteriales, and Methanopyrales orders, that mainly use $\mathrm{H}_{2} / \mathrm{CO}_{2}$ or formate as substrates for methanogenesis, Class II comprises Methanosarcinales and Methanomicrobiales that use methyl compounds (acetate, methanol, methylamines) for methanogenesis (Bapteste et al. 2005). Methanomicrobiales are physiologically more similar to Class I methanogens, but phylogenetically more closely related to the Class II Methanosarcinales (Anderson et al. 2009a, b). The availability of more sequenced genomes of Methanomicrobiales revealed that, though Methanomicrobiales share features of both Class I methanogens and Methanosarcinales, they also have unique properties. As a result of this genomic analysis, the class III of methanogens was proposed to include the order Methanomicrobiales.

\section{Metagenomics}

Metagenomic studies can proportionate the characterization of the previously uncultured microbiota and their potential metabolic capacities in engineered ecosystems. The adaptation of shotgun metagenomics, used to obtain complete genomes from pure cultures, to the analysis of simple microbial communities (those in which a small amount of the species is dominant; e.g. enrichments), allows to obtain near complete genomes of dominant microorganisms within the community (Supplementary Table 2; Fig. 4). Today, the availability of next-generation sequencing (NGS) techniques, such as the Roche/454's GS FLX Titanium, the Illumina/Solexa's GAII or the Life/APG's SOLiD 3 of Applied Biosystems, are replacing expensive and labor intensive Sanger sequencing method, since enormous volume of data can be obtained and the time and cost requirements for sequencing large genomes is drastically reduced (Metzker 2010). In more complex communities, such as those generally found in WWTP, metagenomics offers the possibility to study their phylogenetic composition and functional potential without prior 


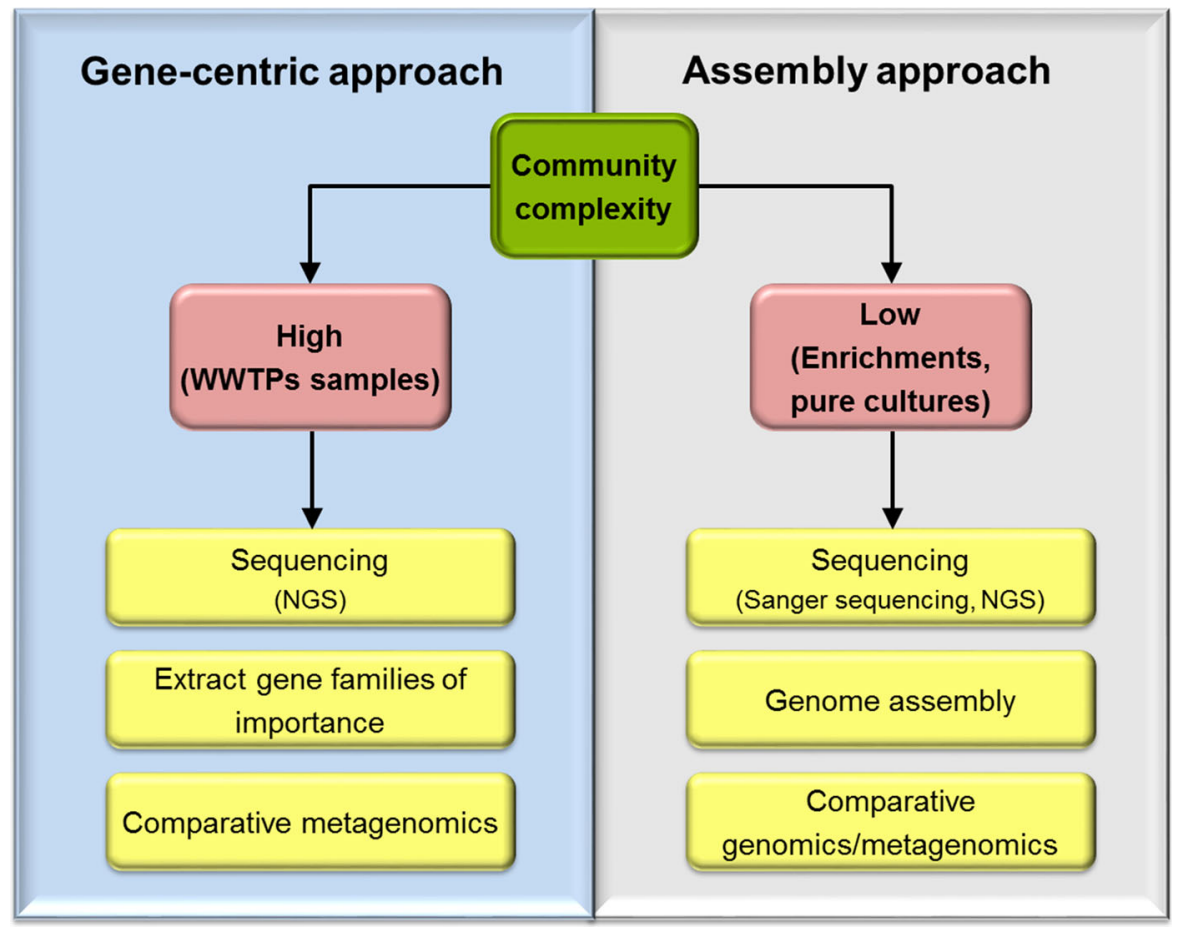

Fig. 4 Metagenomics: the assembly versus the gene-centric approach

enrichment (Albertsen et al. 2012). Moreover, comparative metagenomis, in which the types, abundance and distribution of genes across metagenomes are compared, allow to understand how genomic differences affect, and are affected by, the abiotic environment (Fig. 4; Wooley et al. 2010).

\subsection{Insights into wastewater microorganisms that are not picked by physiology/enrichment approaches}

A gene-centric approach in metagenomics allows insight into the vast majority of wastewater microorganisms that are difficult to cultivate or enrich. Pyrosequencing of an aerobic sludge from a petroleum refinery WWTP enriched for phenol degradation (Silva et al. 2012), showed the great metabolic versatility and huge bacterial diversity of the system. The microbial community showed potential to degrade other organic and xenobiotic compounds than phenol (genes for toluene, naphthalene, benzoate degradation were found). Previous works have reported huge bacterial diversity of wastewater treatment sludges (Miura et al. 2013; Sanapareddy et al.
2009; Silva et al. 2010). This is of particular interest, since maximizing bacterial diversity in wastewater treatment ecosystems has been shown as a way to maintain functional redundancy within microbial communities, thus being a strategy to better cope with variability of input wastewater or other disturbances (McMahon et al. 2007). Even the use of engineered disturbances has been proposed as a control strategy of community assembly and thus process stability (McMahon et al. 2007).

The dominant and non-dominant microbial groups within a microbial community can be addressed by metagenomics, but coverage of non-dominant groups seem to vary depending of the sequencing technique employed. For example, the same community was analyzed by different technologies in a productionscale biogas fermenter fed with renewable primary products (Jaenicke et al. 2011; Schluter et al. 2008). Both studies showed Clostridia as the most prevalent taxonomic class that was likely involved in cellulose degradation, and the order Methanomicrobiales as dominant among methanogens. However, as compared to the GS FLX platform, the GS FLX Titanium platform obtained a 3.5-fold coverage into the non- 
abundant microbial groups, thus resulting in the identification of additional genera and functional elements (Schluter et al. 2008; Jaenicke et al. 2011). The analysis of a different biogas fermenter fed with a substrate mix with similar composition than the above mentioned (plant biomass and pig manure slurry) by using the Applied Biosystems SOLiDTM 4 sequencing platform (Wirth et al. 2012), released similar results regarding to the systematic and functional contexts of the community (Clostridia as key players in the hydrolysis of the plant biomass through cellulose degradation and hydrogen production and Mehanomicrobiales as dominant among methanogens). Regardless of the sequencing technique used, the studies aforementioned allowed to insight into the composition and gene contents of the hydrolytic consortia within the community. Due to hydrolysis of organic matter constitutes a significant limiting step for biogas production, knowledge on the composition and genetic properties of hydrolytic bacteria is essential to optimize initial steps in the decomposition of substrates for biogas production (Schluter et al. 2008). In the same way, the studies highlighted the key role of hydrogenotrophic methanogenesis in the system. Metagenome reads assigned to the archaeal genus Methanoculleus represented high-affinity membranebound hydrogenases, which would ensure an efficient hydrogen oxidation in the course of methanogenesis, resulting in an efficient biogas production.

\subsection{Insights into dominant players in WWTPS communities}

\subsubsection{Understating evolutionary history and adaptations to the environment}

From an activated sludge enrichment culture, the genome of "Candidatus Nitrospira defluvii", a predominant NOB in WWTP (Daims et al. 2006; Nielsen et al. 2010), was reconstructed, shedding light on the nitrification process and clarifying the evolutionary history of this nitrite oxidizer (Lucker et al. 2010). "Candidatus Nitrospira defluvii" differs much from other known nitrite oxidizers (i.e. the proteobacterial NOB Nitrobacter and Nitrococcus) in the key enzyme nitrite oxidoreductase (NXR), which is a periplasmically oriented NXR (Box 2), the composition of the respiratory chain, and the pathway used for autotrophic carbon fixation, suggesting multiple independent evolution of chemolithoautotrophic nitrite oxidizing microorganisms. From the metagenome of this bacterium, an unexpected evolutionary link between Nitrospira and anammox organisms, which share the periplasmic forms of NXR (Box 2) and other proteins, was observed. A later work showed an evolutionary link also between Nitrospina (a marine nitrite oxidizer), Nitrospira and anammox bacteria, apparently including the horizontal transfer of the periplasmically oriented nitrite oxidoreductase and other key genes for nitrite oxidation at an early evolutionary stage (Lucker et al. 2013) (Box 2). Other important characteristics were revealed from the metagenome of "Candidatus Nitrospira defluvii", such as its adaptation to substratelimited conditions and its lack of most classical defense mechanisms against oxidative stress, suggesting that a good aeration control is crucial for maintaining stable and active populations of these organisms in engineered systems (Lucker et al. 2010).

\subsubsection{Metagenomics enables comparative analysis of wastewater microorganisms}

Anammox bacteria are involved in one of the three main processes to remove nitrogen from wastewaters (nitrification, denitrification, anaerobic ammonium oxidation-anammox). However, none of them has been obtained as pure cultures, thus being metagenomics a key method to access their genomes and get a better understanding of these important wastewater microorganisms. The first obtained metagenome, that of the anammox bacterium "Candidatus Kuenenia stuttgartiensis" (Supplementary Table 2) allowed to deduce the metabolic pathway of the anammox reaction, which comprises four enzymatic steps, generating the intermediates nitrite, nitric oxide, and nitrous oxide (Fig. 5), and revealed the presence of genes involved in the acetyl-CoA-pathway for autotrophic carbon fixation (Strous et al. 2006). The high number of genes detected involved in catabolism and respiration, confirmed the versatility of this anammox bacterium with respect to the use of different electron donors and acceptors.

In the last years, the number of anammox metagenomes has increased including: a marine species "Candidatus Scalindua profunda" (van de Vossenberg et al. 2013), two wastewater species, KSU-1 and "Candidatus Jettenia asiatica" (Hira et al. 2012; $\mathrm{Hu}$ et al. 2012) and a freshwater species "Candidatus Brocadia fulgida" (Gori et al. 2011). 


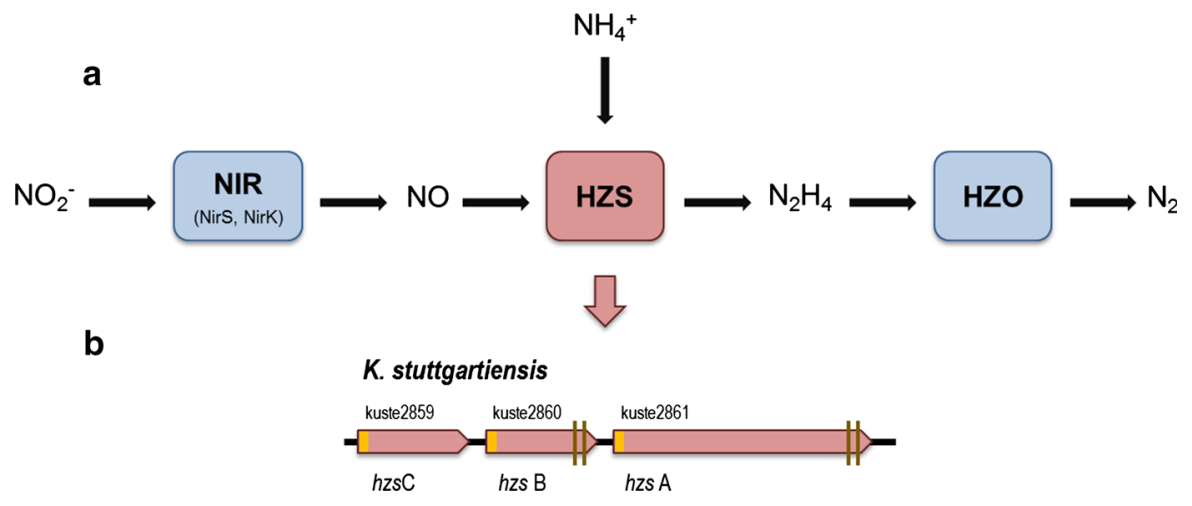

Fig. 5 a Key reactions in nitrogen catabolism of anammox bacteria: (1) reduction of nitrite to nitric oxide by a nitrite reductase (NIR), (2) condensation of ammonium and nitric oxide into hydrazine by a hydrazine synthase (HZS), (3) oxidation of hydrazine into dinitrogen gas by an hydrazine

Comparative analyses of the anammox metagenomes (Gori et al. 2011; Hu et al. 2012; van de Vossenberg et al. 2013) have shown that the enzyme hydrazine synthase (HZS), is a unique protein complex very well conserved in anammox bacteria (Fig. 5). In fact, the $\alpha$-subunit of the hydrazine synthase (hzsA) has been used as a molecular marker (phylomarker) to detect and quantify anammox bacteria (Harhangi et al. 2012; Russ et al. 2013), which highlights the high value of metagenomic studies for the development of further applications. Differences in gene repertories have been found too between the different anammox metagenomes. For example in the enzymes that catalyze the reduction of nitrite to nitric oxide (Fig. 5). This step is catalyzed by a cd1 nitrite reductase (NirS) protein in "Candidatus Kuenenia stuttgartiensis" and "Candidatus Scalindua profunda", while in "Candidatus Jettenia asiatica", "Candidatus Brocadia fulgida" and strain KSU-1 a copper-containing nitrite reductase (NirK) is used, indicating different alternatives to convert nitrite to NO. Also, differences in genes involved in inorganic nitrogen transport have been observed. The metagenomes of "Candidatus Scalindua profunda", "Candidatus Kuenenia stuttgartiensis" and "Candidatus Jettenia asiatica" possess multiple genes encoding focA, a formate/nitrite transport protein, which might give them the advantage to inhabit in environments with low inorganic nitrogen compounds concentrations. In contrast, "Candidatus Brocadia fulgida" possesses only one gene, which may reflect its adaptation to more resource-abundant environments. In fact, relatively higher rates of this bacterium in the presence of oxidoreductase (HZO). b Organization of HZS genes in Kuenenia stuttgartiens. The HZS genes, encoded by the gene cluster ( $h z s C B A)$ (kuste2859-2861-2861), are very well conserved in anammox bacteria

ammonium, nitrite and propionate have been observed, as compared to other anammox microorganisms (Kartal et al. 2008). This knowledge is crucial to understand which anammox microorganisms will develop in bioreactors depending on the wastewater characteristics. Even differences at the species level exist; from the metagenomes of two geographically distant "Candidatus Kuenenia stuttgartiensis" strains (RU1 and CH1) (Speth et al. 2012), it was observed that approximately 369 genes were absent from CH1 strain. Likely, mobile genetic elements are responsible for this variation that appear to emerge as an adaptative response to the environmental characteristics.

As more anammox metagenomes become available, specific metabolic features of these bacteria will be discovered, which will help to understand how genomic differences affect the behavior of these microorganisms in WWTPs. This knowledge could be used to better select the inoculum for the treatment of wastewaters with specific properties. Metagenomic data are also essential for the design of new molecular biomarkers that allow the detection of these slow growing bacteria, by for example quantitative PCR. In fact, qPCR has been used as a reliable indicator for growth of the anammox populations (van der Star et al. 2007, 2008).

\subsubsection{Insights that help towards the isolation of key players}

The metagenomic analysis of samples from two sequencing batch reactors (SBRs) previously enriched 
in the polyphosphate-accumulating organism (PAO) "Candidatus Accumulibacter phosphatis", allowed to obtain the near complete genome of this microorganism, and provided a blue print and understanding for the EBPR process (Martin et al. 2006). High-affinity orthophosphate $(\mathrm{Pi})$ transporter genes in "Candidatus Accumulibacter phosphatis" were detected, which are important to ensure very low $\mathrm{Pi}$ concentrations in the treated wastewater. Metagenomic data allowed to reconstruct the EBPR metabolic model of Accumulibacter, clarifying controversial aspects such as the source of reducing power $(\mathrm{NADP}(\mathrm{H}))$ necessary for anaerobic polyhydroxyalkanoates (PHA) production. Two different mechanisms were proposed. In the first, $\mathrm{NAD}(\mathrm{P}) \mathrm{H}$ would be provided by glycogen degradation and the full anaerobic functioning of the TCA cycle. The discovery of a novel cytochrome $b / b 6$ supports this hypothesis since this protein would function for the necessary reoxidation of reduced quinones produced by succinate dehydrogenase, thus supporting an anaerobic functionality of the TCA cycle. An alternative scenario to full anaerobic functioning of the TCA cycle is the operation of a partial reductive TCA cycle (from oxaloacetate to succinyl-CoA), under anaerobic conditions, as fumarate reductase, which reduces fumarate to succinate, was present in the metagenome of Accumulibacter. From metagenomic data, Mino and Satoh (2006) suggested that these two alternative pathways would act in the cell as a redox balance regulation mechanism when PAOs take up some carbon sources, such as lactate, and store them as PHA with concomitant consumption of excess reducing power. When the cell was using the normal TCA cycle, a succinate dehydrogenase would be active and reducing power would be produced, but when the TCA cycle was operating in reverse, $\mathrm{NAD}(\mathrm{P}) \mathrm{H}$ would be consumed via a fumarate reductase. The fact that $A$. phosphatis contains fumarate reductase means that it should be able to use substrates other than acetate and propionate under anaerobic conditions, which would provide this bacterium with an advantage in the rapidly changing conditions of an EBPR sludge (Mino and Satoh 2006). These and other metabolic and ecological insights, which were deduced from the A. phosphatis metagenome, help to understand the EBPR process and provide important clues for the isolation of Accumulibacter PAOs as pure cultures. Moreover, genes, enzymes and metabolites involved in carbon and phosphorus transformation pathways may be used as functional biomarkers for determining and monitoring phosphorus removal in wastewater treatment systems.

\subsubsection{Insights into syntrophic bacteria in wastewater treatment systems}

Methane production in anaerobic reactors largely depends on syntrophic interactions, thus, knowledge about new syntrophic microorganisms and their metabolic capabilities is essential to control and optimize methane yields. The near complete genome of a non-dominant potentially new syntrophic microorganism, "Candidatus Cloacamonas acidaminovorans", has been obtained from an anaerobic digester without prior enrichment (Pelletier et al. 2008; Supplementary Table 2). The genome of this microorganism revealed the presence of genes for several hydrogenases and five different ferredoxin oxidoreductases which suggested its potential syntrophic lifestyle. A metagenomic assembly approach used in a hyper-mesophilic reactor previously enriched for terephthalate (TA) degradation seeded light on the species interactions within the consortia and allow to explained how TA degradation occurred (Lykidis et al. 2011; Supplementary Table 2). Only partial microbial genomes of the dominant microorganisms (Pelotomaculum, Thermotogae, Syntrophus and representatives of the candidate phyla OP5) could be obtained, however this work showed that TA degradation was not a simply syntrophic interaction between $\mathrm{H}_{2}$-producing bacteria and methanogenic archaea, but additional secondary syntrophic interactions took place to maintain the stability of the TAdegrading community.

\subsubsection{Potential role of transposable and phages elements}

The metagenome of the activated sludge of a nonEBPR WWTP and an EBPR WWTP (Supplementary Table 3) showed the prevalence of transposases (Albertsen et al. 2012; Sanapareddy et al. 2009). This make sense since these enzymes, which catalyzes the movement of transposons to another part of the genomes, are important in creating genetic diversity and adaptability in environments with changing living conditions (Aziz et al. 2010), such as those present in nutrient removal WWTP. Both studies also 
highlighted the lack of reference genomes as a main limitation to study these WWTPs in detail.

In the study of the full scale EBPR WWTP (Albertsen et al. 2012) high numbers of phage proteins were identified in the metagenome. Phages have been found to affect dynamics of Accumulibacter populations (Albertsen et al. 2013; Barr et al. 2010; Kunin et al. 2008) and thus, deeply-sequencing metagenomic studies would be relevant for identifying the active phages and designing phage-control strategies in fullscale WWTPs. Only $15 \%$ of the reads matching Accumulibacter had a high similarity $(<95 \%)$ to the sequenced Accumulibacter clade IIA strain UW-1 genome, indicating the presence of some microdiversity. This microdivesrity seems to respond to a selective pressure from phages, since the main differences between the reference genome and the Accumulibacter strains present in the metagenome were related to phage predation and defense.

\section{Metatranscriptomics and metaproteomics}

To really uncover what functions the community members are carrying out under specific conditions, the metatranscriptome or metaproteome (collective mRNA or protein from all organisms present in a biological ecosystem) must be analyzed. Challenges associated with the application of metaproteomics have been extensively reviewed (Roh et al. 2010; Simon and Daniel 2011; Sorek and Cossart 2010; Wagner et al. 2007). Several techniques have been used, but currently, direct cDNA sequencing trough NGS is the most viable alternative (Chistoserdova 2010; Roh et al. 2010) (Fig. 2). Metaproteomics, also known as environmental proteomics, community proteomics and community proteogenomics (Schneider and Riedel 2010) allows detection of key enzymes involved in important metabolic pathways and correlates them with expression and genomic profiles of microbial populations. Techniques used and challenges associated to this approach have been discussed in several works (Lo et al. 2007; Schneider and Riedel 2010; Wilmes and Bond 2006a).

Metaproteomic and metatransciptomic studies applied to wastewater treatment are listed in Supplementary Tables 4 and 5. Metaproteomics of mixed cultures from a continuous-flow wastewater treatment bioreactor that was fed a mixture of twelve organic chemicals (acetone, 2-butanone, 2-hexanone, phenol, p-cresol, 2,4-dimethyl phenol, benzene, toluene, $\mathrm{m}$-xylene, chlorobenzene, 1,4-dichlorobenzene, and 1,2,4-trichlorobenzene) and exposed to the toxic cadmium have provided functional information about the response of microbial communities to a chemical stress (Lacerda et al. 2007). Proteomic analysis revealed significant shifts in the microbial community physiology within $15 \mathrm{~min}$ of cadmium exposure, a rapid change not detectable using the phylogenetic profiling tools common to molecular microbial ecology. Moreover, significant community proteome responses after $0.25,1,2$, and $3 \mathrm{~h}$ of exposure to cadmium were observed, with more than 100 protein expression changes detected at each time point, suggesting that the community's short-, medium-, and long-term responses to this stress were different. More than 100 unique differentially expressed proteins, including proteins of importance in the cadmium shock such as ATPases, oxidoreductases, and transport proteins were identified.

Abram et al. (2011) used metaproteomics to provide functional evidence of key metabolic pathways from an anaerobic EGSB reactor treating synthetic glucose-based wastewater. They could identify proteins of relevant metabolic pathways taking place in the bioreactor, such as glucose degradation via glycolysis and the pentose phosphate pathway, and the production of methane via methanogenesis from both $\mathrm{CO}_{2}$ and acetate. Metaproteomics allowed to uncover key biochemical metabolic pathways occurring in the bioreactor. By using this technique, it might also be possible to identify enzymatic markers, or temporal shifts in the protein expression patterns in the microbial communities, which could be used as predictive indicators of process failure (Abram et al. 2011).

Yu and Zhang (2012) conducted a metatranscriptomic work on nitrogen removal in a full-scale WWTP. Through metagenomics and metatranscriptomics by Illumina sequencing of the activated sludge community, they found differences between the DNA and cDNA datasets with regards to microbial community composition and gene expression. Despite that the nitrification-related genes showed a low abundance in DNA datasets, the cDNA datasets suggested a strong nitrification activity, which highlights the importance of gene expression analyses in detecting active populations within the community. Kuhn et al. 
(2011) investigated five aerobic membrane biological reactors (MBR) fed with municipal wastewater, but with different configurations and applications (two of them were configured for carbon removal, another two for carbon and nitrogen removal and one of them exhibited carbon, nitrogen and phosphorus removal). Most of the MBR performed nitrification, thus the detection of proteins from the AOB Nitrosomonas europaea was expected. However, proteins from bacteria not previously found in wastewater treatment systems were detected too. The authors also found the protein elastase-a human protease from pancreasin all MBR samples, suggesting that this protease is a significant constituent of municipal wastewater.

Several studies have focused on the study of protein and gene expression of Accumulibacter-enriched EBPR sludges or activated sludge communities. Preliminary metaproteomic studies on lab-scale activated sludge systems enriched in Accumulibacter demonstrated a strong similarity in protein profiles under anaerobic and aerobic conditions of the EBPR process (Wilmes and Bond 2004, 2006b). This was further confirmed by subsequent metaproteomic and metatranscriptomic analyses of Accumulibacter-enriched populations from different local WWTPs (He et al. 2010; Wexler et al. 2009; Wilmes et al. 2008a). As a possible explanation for this, He et al. (2010) suggested that the majority of genes involved in EBPR are constitutively expressed at low levels during an EBPR cycle, which may give a selective advantage to Accumulibacter through a better response under fluctuating conditions existing in WWTPs. Genes that were upregulated aerobically involved functions such as the TCA cycle, ATP synthesis, transcription, translation and protein translocation, supporting EBPR metabolic models that the oxidation of intracellularly stored carbon provides ATP for cell growth when oxygen becomes available (He et al. 2010). The metatranscriptomic analysis of Accumulibacter of $\mathrm{He}$ et al. (2010) reinforced hypotheses previously inferred from the metagenomic analysis (Martin et al. 2006), e.g. NADP $(\mathrm{H})$ for PHA production under anaerobic conditions is likely derived from the operation of the TCA cycle together with glycogen degradation. The study confirmed the expression of genes previously hypothesized to be involved in EBPR process, such as for PHA synthesis and polyphosphate formation, and novel genes such as genes for extracellular polymeric substances (EPS) formation, should be of importance for Accumulibacter survival in its environment. Consistent results were observed from both the metatranscriptomic (He et al. 2010) and metaproteomics analyses (Wilmes et al. 2008a, b) for example in the detection of the fatty acid beta-oxidation pathway. Significant differences in gene detection were found for genes involved in EPS formation and denitrification, which could be due to the fact that different Accumulibacter clades were analyzed in the studies, clade IIA (He et al. 2010) and clades I and IID (Wilmes et al. 2008b). These results also highlight the necessity for more genomic and post-genomic studies on other Accumulibacter clades to gain knowledge on the physiological characteristics, ecological niches and functions. This knowledge would be crucial in optimizing EBPR process in full-scale WWTPs.

\section{Applications in wastewater biotechnology: future perspectives}

Meta-omics holds a great potential for discovering novel microbial clades or enzymes that are relevant for wastewater treatment. A better knowledge on the composition and functional dynamics of microbial communities will have a far-reaching impact in the wastewater treatment sector by allowing the development of new or improved processes and innovative bioreactor designs. Omics-generated information can be used to direct bioaugmentation strategies, likely using enriched cultures, and to change plant operational parameters to favor certain phylogenetic groups or to steer metabolic pathways. Success of bioaugmentation is often dependent on WWTP operation parameters and, therefore, these two aspects can be mutually dependent. Bioaugmentation has been successfully applied for several full- and lab-scale cases. Most of the bioaugmentation trials were performed with pure cultures, and therefore highly dependent on available isolates (Bouchez et al. 2009; Duque et al. 2011; Ikeda-Ohtsubo et al. 2013; Lenz et al. 2009). Enriched cultures have also been used with promising results, e.g. in phosphorus removal (Dabert et al. 2005) and for the treatment of hypersaline wastewaters (Shi et al. 2012). In both approaches, selection of bioaugmenting inoculum is based on the principle that certain microorganisms are better suited for a required catabolic task than others, due to their physiological properties, or often just because they have been found 
to be predominant in environments where the specific catabolic route occurs.

Metagenomics allows us to obtain more in-depth and representative coverage of the microbial groups and catabolic genes present in WWTP. Thereby it can uncover previously not identified phylogenetic groups or novel metabolic pathways. These data could give important clues to which microbes might be beneficial in bioaugmentation, allowing for the introduction and/ or improved enrichment of the desired microbes in the WWTP sludge. Besides this, phylogenetic relatedness of newly identified phylotypes to cultured relatives could foster their isolation from WWTP sludge, allowing for further ecophysiological and bioaugmentation studies. There are few examples of uncultivated bacteria that have been isolated from complex ecosystems using meta-genomics/transcriptomics information (Bomar et al. 2011; Tyson et al. 2005). Tyson et al. (2005) isolated Leptospirillum ferrodiazotrophum from an acid mine drainage biofilm after discovering that a minor member of the community had a single nitrogen fixation operon (nifHD-KENX). This finding, which was detected by random shotgun sequencing, suggested a simple directed isolation strategy by serial dilution in nitrogen-free liquid medium. Using meta-transcriptomics, Bomar et al. (2011) were able to show that an uncultured Rikenellalike leech gut symbiont was able to forage on host mucin glycans. The high expression levels of a sulfated-mucin desulfatase $(s m d S 1)$ and endo- $\beta-N$ acetylglucosaminidase (endoG) genes strongly suggested that mucins were the main source of energy and carbon for the Rikenella-like bacterium. This enabled the cultivation of the Rikenella-like bacterium in a mucin-containing medium. The strategies described in these examples prove the potential of -omics tools to predict the adequate environmental conditions or the right selective pressure to steer microbial communities.

Much progress can be gained in wastewater treatment processes through the exploitation of this potential to identify new microorganisms. Not only can more microorganisms that can further serve as bioaugmenting strains be isolated, but also operational bioreactor conditions can be defined and improved based on the omics-based knowledge. It is presently known that some SRB can switch from sulfidogenic to syntrophic metabolism (Plugge et al. 2011); these microorganisms might be ideal for the treatment of wastewaters with low concentration of sulfate, as they can efficiently convert sulfate and then work together with methanogens for biogas production. In fact, Desulfovibrio species became the main lactate-fermenting bacteria in an anaerobic reactor degrading whey (Chartrain and Zeikus 1986). EBPR processes are also rather complex with competing reactions between polyphosphate accumulating organisms (PAOs) and glycogen accumulating organisms (GAOs). Population dynamics and metabolic diversity of PAOs and GAOs has been tentatively modeled already including metagenomic information on PAO (Martin et al. 2006; Oehmen et al. 2010). More genomic data on the different clades of Accumulibacter are necessary (Martin et al. 2006; He et al. 2010) to understand its different physiological properties and for further transcriptomic and proteomic analyses that will help to understand the EBPR process and which are the operational conditions that favor the presence of each Accumulibacter clade in bioreactors. Metaomic information allows us to understand syntrophic interactions between microbes, not only in wastewater treatment systems but also in bioremediation sites (Lykidis et al. 2011; Maphosa et al. 2012).

The development of predictive models for distilling the main processes that drive the bioreactor systems largely depends on the generation of meta-omic information. Today, flux balance analysis (FBA) is one promising approach for metabolic modeling of microorganisms, since it does not require kinetic parameters for the reactions involved and can be scaled to deal with complete genomes (McMahon et al. 2007). However, novel computational approaches are needed that allow the interpretation and integration of meta-omic datasets (Roling et al. 2010). Meta-omic approaches are also powerful tools for the development of specific biomarkers or the analysis of protein expression patterns of the microbial communities that could be used as predictive indicators of process performance, aiding in the monitoring and control of wastewater treatment processes.

Acknowledgments This research was supported by the Spanish Ministry of Education and Science (Contract Project CTQ2007-64324 and CONSOLIDER-CSD 2007-00055) and the Regional Government of Castilla y Leon (Ref. VA038A07). Research of AJMS is supported by the European Research Council (Grant 323009). 


\section{References}

Abram F, Enright AM, O'Reilly J, Botting CH, Collins G, O'Flaherty V (2011) A metaproteomic approach gives functional insights into anaerobic digestion. J Appl Microbiol 110:1550-1560. doi:10.1111/j.1365-2672.2011. 05011.x

Albertsen M, Hansen LB, Saunders AM, Nielsen PH, Nielsen KL (2012) A metagenome of a full-scale microbial community carrying out enhanced biological phosphorus removal. ISME J 6:1094-1106. doi:10.1038/ismej.2011.176

Albertsen M, Saunders AM, Nielsen KL, Nielsen PH (2013) Metagenomes obtained by 'deep sequencing' - what do they tell about the enhanced biological phosphorus removal communities? Water Sci Technol 68:1959-1968. doi:10.2166/wst.2013.441

Anderson I, Ulrich LE, Lupa B, Susanti D, Porat I, Hooper SD, Lykidis A, Sieprawska-Lupa M, Dharmarajan L, Goltsman E, Lapidus A, Saunders E, Han C, Land M, Lucas S, Mukhopadhyay B, Whitman WB, Woese C, Bristow J, Kyrpides N (2009a) Genomic characterization of methanomicrobiales reveals three classes of methanogens. PLoS ONE 4:e5797. doi:10.1371/journal.pone.0005797

Anderson IJ, Sieprawska-Lupa M, Lapidus A, Nolan M, Copeland A, Del Rio TG, Tice H, Dalin E, Barry K, Saunders E, Han C, Brettin T, Detter JC, Bruce D, Mikhailova N, Pitluck S, Hauser L, Land M, Lucas S, Richardson P, Whitman WB (2009b) Kyrpides NCComplete genome sequence of Methanoculleus marisnigri Romesser et al. 1981 type strain JR1. Stand Genomic Sci 1:189-196. doi:10.4056/sigs.32535

Aoi Y, Shiramasa Y, Tsuneda S, Hirata A, Kitayama A, Nagamune $T$ (2002) Real-time monitoring of ammonia-oxidizing activity in a nitrifying biofilm by amoA mRNA analysis. Water Sci Technol 46(1-2):439-442

Aoi Y, Shiramasa Y, Masaki Y, Tsuneda S, Hirata A, Kitayama A, Nagamune T (2004) Expression of amoA mRNA in wastewater treatment processes examined by competitive RT-PCR. J Biotechnol 111(2):111-120

Arp DJ, Chain PS, Klotz MG (2007) The impact of genome analyses on our understanding of ammonia-oxidizing bacteria. Annu Rev Microbiol 61:503-528

Aziz RK, Breitbart M, Edwards RA (2010) Transposases are the most abundant, most ubiquitous genes in nature. Nucleic Acids Res 38:4207-4217. doi:10.1093/nar/gkq140

Bakken LR, Bergaust L, Liu B, Frostegard A (2012) Regulation of denitrification at the cellular level: a clue to the understanding of $\mathrm{N}_{2} \mathrm{O}$ emissions from soils. Philos Trans R Soc Lond B Biol Sci 367:1226-1234. doi:10.1098/rstb.2011. 0321

Bapteste E, Brochier C, Boucher Y (2005) Higher-level classification of the Archaea: evolution of methanogenesis and methanogens. Archaea (Vancouver, BC) 1:353-363

Barr JJ, Slater FR, Fukushima T, Bond PL (2010) Evidence for bacteriophage activity causing community and performance changes in a phosphorus-removal activated sludge. FEMS Microbiol Ecol 74:631-642. doi:10.1111/j.15746941.2010.00967.x

Beaumont HJ, Lens SI, Reijnders WN, Westerhoff HV, van Spanning RJ (2004) Expression of nitrite reductase in
Nitrosomonas europaea involves NsrR, a novel nitritesensitive transcription repressor. Mol Microbiol 54(1): 148-158

Berube PM, Stahl DA (2012) The divergent AmoC3 subunit of ammonia monooxygenase functions as part of a stress response system in Nitrosomonas europaea. J Bacteriol 194(13):3448-3456

Bollmann A, Sedlacek CJ, Norton J, Laanbroek HJ, Suwa Y, Stein LY, Klotz MG, Arp D, Sayavedra-Soto L, Lu M, Bruce D, Detter C, Tapia R, Han J, Woyke T, Lucas SM, Pitluck S, Pennacchio L, Nolan M, Land ML, Huntemann M, Deshpande S, Han C, Chen A, Kyrpides N, Mavromatis K, Markowitz V, Szeto E, Ivanova N, Mikhailova N, Pagani I, Pati A, Peters L, Ovchinnikova G, Goodwin LA (2013) Complete genome sequence of Nitrosomonas sp. Is79, an ammonia oxidizing bacterium adapted to low ammonium concentrations. Stand Genomic Sci 7(3):469-482

Bomar L, Maltz M, Colston S, Graf J (2011) Directed culturing of microorganisms using metatranscriptomics. mBio 2:e00012-00011. doi:10.1128/mBio.00012-11

Bouchez T, Patureau D, Delgenes JP, Moletta R (2009) Successful bacterial incorporation into activated sludge flocs using alginate. Bioresour Technol 100:1031-1032. doi:10. 1016/j.biortech.2008.07.028

Chain P, Lamerdin J, Larimer F, Regala W, Lao V, Land M, Hauser L, Hooper A, Klotz M, Norton J, Sayavedra-Soto L, Arciero D, Hommes N, Whittaker M, Arp D (2003) Complete genome sequence of the ammonia-oxidizing bacterium and obligate chemolithoautotroph Nitrosomonas europaea. J Bacteriol 185(9):2759-2773

Chartrain M, Zeikus JG (1986) Microbial ecophysiology of whey biomethanation: characterization of bacterial trophic populations and prevalent species in continuous culture. Appl Environ Microbiol 51:188-196

Chistoserdova L (2010) Recent progress and new challenges in metagenomics for biotechnology. Biotechnol Lett 32: 1351-1359. doi:10.1007/s10529-010-0306-9

Colliver BB, Stephenson T (2000) Production of nitrogen oxide and dinitrogen oxide by autotrophic nitrifiers. Biotechnol Adv 18(3):219-232

Dabert P, Delgenes JP, Godon JJ (2005) Monitoring the impact of bioaugmentation on the start up of biological phosphorus removal in a laboratory scale activated sludge ecosystem. Appl Microbiol Biotechnol 66:575-588. doi:10.1007/ s00253-004-1726-z

Daims H, Taylor MW, Wagner M (2006) Wastewater treatment: a model system for microbial ecology. Trends Biotechnol 24:483-489. doi:10.1016/j.tibtech.2006.09.002

Duque AF, Bessa VS, Carvalho MF, de Kreuk MK, van Loosdrecht MC, Castro PM (2011) 2-fluorophenol degradation by aerobic granular sludge in a sequencing batch reactor. Water Res 45:6745-6752. doi:10.1016/j.watres.2011.10. 033

Galagan JE, Nusbaum C, Roy A, Endrizzi MG, Macdonald P, FitzHugh W, Calvo S, Engels R, Smirnov S, Atnoor D, Brown A, Allen N, Naylor J, Stange-Thomann N, DeArellano K, Johnson R, Linton L, McEwan P, McKernan K, Talamas J, Tirrell A, Ye W, Zimmer A, Barber RD, Cann I, Graham DE, Grahame DA, Guss AM, Hedderich R, Ingram-Smith C, Kuettner HC, Krzycki JA, Leigh JA, Li 
W, Liu J, Mukhopadhyay B, Reeve JN, Smith K, Springer TA, Umayam LA, White O, White RH, Conway de Macario E, Ferry JG, Jarrell KF, Jing H, Macario AJ, Paulsen I, Pritchett M, Sowers KR, Swanson RV, Zinder SH, Lander E, Metcalf WW, Birren B (2002) The genome of M. acetivorans reveals extensive metabolic and physiological diversity. Genome Res 12:532-542. doi:10.1101/gr.223902

Gori F, Tringe SG, Kartal B, Marchiori E, Jetten MS (2011) The metagenomic basis of anammox metabolism in Candidatus 'Brocadia fulgida'. Biochem Soc Trans 39:1799-1804. doi:10.1042/BST20110707

Handelsman J, Rondon MR, Brady SF, Clardy J, Goodman RM (1998) Molecular biological access to the chemistry of unknown soil microbes: a new frontier for natural products. Chem Biol 5:R245-R249

Harhangi HR, Le Roy M, van Alen T, Hu BL, Groen J, Kartal B, Tringe SG, Quan ZX, Jetten MS, Op den Camp HJ (2012) Hydrazine synthase, a unique phylomarker with which to study the presence and biodiversity of anammox bacteria. Appl Environ Microbiol 78:752-758. doi:10.1128/aem. 07113-11

Hauser LJ, Land ML, Brown SD, Larimer F, Keller KL, RappGiles BJ, Price MN, Lin M, Bruce DC, Detter JC, Tapia R, Han CS, Goodwin LA, Cheng JF, Pitluck S, Copeland A, Lucas S, Nolan M, Lapidus AL, Palumbo AV, Wall JD (2011) Complete genome sequence and updated annotation of Desulfovibrio alaskensis G20. J Bacteriol 193:42684269. doi:10.1128/JB.05400-11

He S, McMahon KD (2011) 'Candidatus Accumulibacter' gene expression in response to dynamic EBPR conditions. ISME J 5:329-340. doi:10.1038/ismej.2010.127

He S, Kunin V, Haynes M, Martin HG, Ivanova N, Rohwer F, Hugenholtz P, McMahon KD (2010) Metatranscriptomic array analysis of 'Candidatus Accumulibacter phosphatis'enriched enhanced biological phosphorus removal sludge. Environ Microbiol 12:1205-1217. doi:10.1111/j.14622920.2010.02163.x

Hendrickson EL, Haydock AK, Moore BC, Whitman WB, Leigh JA (2007) Functionally distinct genes regulated by hydrogen limitation and growth rate in methanogenic Archaea. Proc Natl Acad Sci USA 104:8930-8934. doi:10. 1073/pnas.0701157104

Hira D, Toh H, Migita CT, Okubo H, Nishiyama T, Hattori M, Furukawa K, Fujii T (2012) Anammox organism KSU-1 expresses a NirK-type copper-containing nitrite reductase instead of a NirS-type with cytochrome cd1. FEBS Lett 586:1658-1663. doi:10.1016/j.febslet.2012.04.041

Hu Z, Speth DR, Francoijs KJ, Quan ZX, Jetten MS (2012) Metagenome analysis of a complex community reveals the metabolic blueprint of Anammox Bacterium "Candidatus Jettenia asiatica". Front Microbiol 3:366. doi:10.3389/ fmicb.2012.00366

Ikeda-Ohtsubo W, Miyahara M, Kim SW, Yamada T, Matsuoka M, Watanabe A, Fushinobu S, Wakagi T, Shoun H, Miyauchi K, Endo G (2013) Bioaugmentation of a wastewater bioreactor system with the nitrous oxide-reducing denitrifier Pseudomonas stutzeri strain TR2. J Biosci Bioeng 115:37-42. doi:10.1016/j.jbiosc.2012.08.015

Jaenicke S, Ander C, Bekel T, Bisdorf R, Droge M, Gartemann KH, Junemann S, Kaiser O, Krause L, Tille F, Zakrzewski M, Puhler A, Schluter A, Goesmann A (2011) Comparative and joint analysis of two metagenomic datasets from a biogas fermenter obtained by 454-pyrosequencing. PLoS ONE 6:e14519. doi:10.1371/journal.pone.0014519

Jenkins D (2008) From total suspended solids to molecular biology tools - a personal view of biological wastewater treatment process population dynamics. Water Environ Res 80:677-687

Kartal B, van Niftrik L, Rattray J, van de Vossenberg JL, Schmid MC, Sinninghe Damste J, Jetten MS, Strous M (2008) Candidatus 'Brocadia fulgida': an autofluorescent anaerobic ammonium oxidizing bacterium. FEMS Microbiol Ecol 63:46-55. doi:10.1111/j.1574-6941.2007.00408.x

Kawakoshi A, Nakazawa H, Fukada J, Sasagawa M, Katano Y, Nakamura S, Hosoyama A, Sasaki H, Ichikawa N, Hanada S, Kamagata Y, Nakamura K, Yamazaki S, Fujita N (2012) Deciphering the genome of polyphosphate accumulating actinobacterium Microlunatus phosphovorus. DNA Res 19:383-394. doi:10.1093/dnares/dss020

Keller KL, Wall JD (2011) Genetics and molecular biology of the electron flow for sulfate respiration in Desulfovibrio. Front Microbiol 2:135. doi:10.3389/fmicb.2011.00135

Keller KL, Rapp-Giles BJ, Semkiw ES, Porat I, Brown SD, Wall JD (2014) New model for electron flow for sulfate reduction in Desulfovibrio alaskensis G20. Appl Environ Microbiol 80:855-868. doi:10.1128/aem.02963-13

Kirstein K, Bock E (1993) Close genetic relationship between Nitrobacter hamburgensis nitrite oxidoreductase and Escherichia coli nitrate reductases. Arch Microbiol 160(6): 447-453

Klotz MG, Arp DJ, Chain PS, El-Sheikh AF, Hauser LJ, Hommes NG, Larimer FW, Malfatti SA, Norton JM, PoretPeterson AT, Vergez LM, Ward BB (2006) Complete genome sequence of the marine, chemolithoautotrophic, ammonia-oxidizing bacterium Nitrosococcus oceani ATCC 19707. Appl Environ Microbiol 72(9):6299-6315

Kristiansen R, Nguyen HT, Saunders AM, Nielsen JL, Wimmer R, Le VQ, McIlroy SJ, Petrovski S, Seviour RJ, Calteau A, Nielsen KL, Nielsen PH (2013) A metabolic model for members of the genus Tetrasphaera involved in enhanced biological phosphorus removal. ISME J 7:543-554. doi:10. 1038/ismej.2012.136

Kuhn R, Benndorf D, Rapp E, Reichl U, Palese LL, Pollice A (2011) Metaproteome analysis of sewage sludge from membrane bioreactors. Proteomics 11:2738-2744. doi:10. 1002/pmic. 201000590

Kunin V, He S, Warnecke F, Peterson SB, Garcia Martin H, Haynes M, Ivanova N, Blackall LL, Breitbart M, Rohwer F, McMahon KD, Hugenholtz P (2008) A bacterial metapopulation adapts locally to phage predation despite global dispersal. Genome Res 18:293-297. doi:10.1101/gr. 6835308

Kuo DH, Robinson KG, Layton AC, Meyers AJ, Sayler GS (2006) Real-time PCR quantification of ammonia-oxidizing bacteria (AOB): solids retention time (SRT) impacts during activated sludge treatment of industrial wastewater. Environ Eng Sci 23(3):507-520

Kuo DH, Robinson KG, Layton AC, Meyers AJ, Sayler GS (2010) Transcription levels (amoA mRNA-based) and population dominance (amoA gene-based) of ammoniaoxidizing bacteria. J Ind Microbiol Biotechnol 37(7): $751-757$ 
Lacerda CM, Choe LH, Reardon KF (2007) Metaproteomic analysis of a bacterial community response to cadmium exposure. J Proteome Res 6:1145-1152. doi:10.1021/ $\operatorname{pr} 060477 \mathrm{v}$

Lenz M, Enright AM, O'Flaherty V, van Aelst AC, Lens PN (2009) Bioaugmentation of UASB reactors with immobilized Sulfurospirillum barnesii for simultaneous selenate and nitrate removal. Appl Microbiol Biotechnol 83:377-388. doi:10.1007/s00253-009-1915-x

Liu B, Frostegard A, Shapleigh JP (2013) Draft genome sequences of five strains in the genus Thauera. Genome Announc. doi:10.1128/genomeA.00052-12

Lo I, Denef VJ, Verberkmoes NC, Shah MB, Goltsman D, DiBartolo G, Tyson GW, Allen EE, Ram RJ, Detter JC, Richardson P, Thelen MP, Hettich RL, Banfield JF (2007) Strain-resolved community proteomics reveals recombining genomes of acidophilic bacteria. Nature 446:537-541. doi: 10.1038 /nature 05624

Lucker S, Wagner M, Maixner F, Pelletier E, Koch H, Vacherie B, Rattei T, Damste JS, Spieck E, Le Paslier D, Daims H (2010) A Nitrospira metagenome illuminates the physiology and evolution of globally important nitrite-oxidizing bacteria. Proc Natl Acad Sci USA 107:13479-13484. doi:10.1073/pnas.1003860107

Lucker S, Nowka B, Rattei T, Spieck E, Daims H (2013) The genome of Nitrospina gracilis illuminates the metabolism and evolution of the major marine nitrite oxidizer. Front Microbiol 4:27. doi:10.3389/fmicb.2013.00027

Lykidis A, Chen CL, Tringe SG, McHardy AC, Copeland A, Kyrpides NC, Hugenholtz P, Macarie H, Olmos A, Monroy O, Liu WT (2011) Multiple syntrophic interactions in a terephthalate-degrading methanogenic consortium. ISME J 5:122-130. doi:10.1038/ismej.2010.125

Maphosa F, van Passel MWJ, de Vos WM, Smidt H (2012) Metagenome analysis reveals yet unexplored reductive dechlorinating potential of Dehalobacter sp. E1 growing in co-culture with Sedimentibacter sp. Environ Microbiol Rep 4:604-616. doi:10.1111/j.1758-2229.2012.00376.x

Martin HG, Ivanova N, Kunin V, Warnecke F, Barry KW, McHardy AC, Yeates C, He S, Salamov AA, Szeto E, Dalin E, Putnam NH, Shapiro HJ, Pangilinan JL, Rigoutsos I, Kyrpides NC, Blackall LL, McMahon KD, Hugenholtz P (2006) Metagenomic analysis of two enhanced biological phosphorus removal (EBPR) sludge communities. Nat Biotechnol 24:1263-1269. doi:10.1038/nbt1247

Maus I, Wibberg D, Stantscheff R, Eikmeyer FG, Seffner A, Boelter J, Szczepanowski R, Blom J, Jaenicke S, Konig H, Puhler A, Schluter A (2012) Complete genome sequence of the hydrogenotrophic, methanogenic archaeon Methanoculleus bourgensis strain MS2(T), Isolated from a sewage sludge digester. J Bacteriol 194:5487-5488. doi:10.1128/ JB.01292-12

McIlroy SJ, Kristiansen R, Albertsen M, Karst SM, Rossetti S, Nielsen JL, Tandoi V, Seviour RJ, Nielsen PH (2013) Metabolic model for the filamentous 'Candidatus Microthrix parvicella' based on genomic and metagenomic analyses. ISME J 7(6):1161-1172. doi:10.1038/ismej. 2013.6

McMahon KD, Martin HG, Hugenholtz P (2007) Integrating ecology into biotechnology. Curr Opin Biotechnol 18:287-292. doi:10.1016/j.copbio.2007.04.007
Metzker ML (2010) Sequencing technologies-the next generation. Nat Rev Genet 11:31-46. doi:10.1038/nrg2626

Mino T, Satoh H (2006) Wastewater genomics. Nat Biotech 24:1229-1230

Miura T, Kusada H, Kamagata Y, Hanada S, Kimura N (2013) Genome sequence of the multiple-beta-lactam-antibioticresistant bacterium Acidovorax sp. strain MR-S7. Genome Announc. doi:10.1128/genomeA.00412-13

Muller EE, Pinel N, Gillece JD, Schupp JM, Price LB, Engelthaler DM, Levantesi C, Tandoi V, Luong K, Baliga NS, Korlach J, Keim PS, Wilmes P (2012) Genome sequence of 'Candidatus Microthrix parvicella' Bio17-1, a long-chainfatty-acid-accumulating filamentous actinobacterium from a biological wastewater treatment plant. J Bacteriol 194:6670-6671. doi:10.1128/JB.01765-12

Nielsen PH, Mielczarek AT, Kragelund C, Nielsen JL, Saunders AM, Kong Y, Hansen AA, Vollertsen J (2010) A conceptual ecosystem model of microbial communities in enhanced biological phosphorus removal plants. Water Res 44:5070-5088. doi:10.1016/j.watres.2010.07.036

Norton JM, Klotz MG, Stein LY, Arp DJ, Bottomley PJ, Chain PS, Hauser LJ, Land ML, Larimer FW, Shin MW, Starkenburg SR (2008) Complete genome sequence of Nitrosospira multiformis, an ammonia-oxidizing bacterium from the soil environment. Appl Environ Microbiol 74(11):3559-3572

Odom JM, Peck HD (1981) Hydrogen cycling as a general mechanism for energy coupling in the sulfate-reducing bacteria, Desulfovibrio sp. FEMS Microbiol Lett 12:47-50. doi:10.1111/j.1574-6968.1981.tb07609.x

Oehmen A, Lopez-Vazquez CM, Carvalho G, Reis MA, van Loosdrecht MC (2010) Modelling the population dynamics and metabolic diversity of organisms relevant in anaerobic/ anoxic/aerobic enhanced biological phosphorus removal processes. Water Res 44:4473-4486. doi:10.1016/j.watres. 2010.06.017

Pelletier E, Kreimeyer A, Bocs S, Rouy Z, Gyapay G, Chouari R, Riviere D, Ganesan A, Daegelen P, Sghir A, Cohen GN, Medigue C, Weissenbach J, Le Paslier D (2008) "Candidatus Cloacamonas acidaminovorans": genome sequence reconstruction provides a first glimpse of a new bacterial division. J Bacteriol 190:2572-2579. doi:10.1128/JB. 01248-07

Pereira IA, Ramos AR, Grein F, Marques MC, da Silva SM, Venceslau SS (2011) A comparative genomic analysis of energy metabolism in sulfate reducing bacteria and archaea. Front Microbiol 2:69. doi:10.3389/fmicb.2011. 00069

Plugge CM, Zhang W, Scholten JC, Stams AJ (2011) Metabolic flexibility of sulfate-reducing bacteria. Front Microbiol 2:81. doi:10.3389/fmicb.2011.00081

Plugge CM, Henstra AM, Worm P, Swarts DC, Paulitsch-Fuchs AH, Scholten JC, Lykidis A, Lapidus AL, Goltsman E, Kim E, McDonald E, Rohlin L, Crable BR, Gunsalus RP, Stams AJ, McInerney MJ (2012) Complete genome sequence of Syntrophobacter fumaroxidans strain (MPOB(T)). Stand Genomic Sci 7:91-106. doi:10.4056/ sigs. 2996379

Potter LC, Millington P, Griffiths L, Thomas GH, Cole JA (1999) Competition between Escherichia coli strains expressing either a periplasmic or a membrane-bound 
nitrate reductase: does Nap confer a selective advantage during nitrate-limited growth? Biochem J 344(Pt 1):77-84

Ramos AR, Keller KL, Wall JD, Pereira IA (2012) The membrane QmoABC complex interacts directly with the dissimilatory adenosine $5^{\prime}$-phosphosulfate reductase in sulfate reducing bacteria. Front Microbiol 3:137. doi:10.3389/ fmicb.2012.00137

Richardson DJ (2000) Bacterial respiration: a flexible process for a changing environment. Microbiology $146(\mathrm{Pt}$ 3):551-571

Rodionov DA, Dubchak IL, Arkin AP, Alm EJ, Gelfand MS (2005) Dissimilatory metabolism of nitrogen oxides in bacteria: comparative reconstruction of transcriptional networks. PLoS Comput Biol 1:e55. doi:10.1371/journal. pcbi.0010055

Roh SW, Abell GC, Kim KH, Nam YD, Bae JW (2010) Comparing microarrays and next-generation sequencing technologies for microbial ecology research. Trends Biotechnol 28:291-299. doi:10.1016/j.tibtech.2010.03.001

Roling WF, Ferrer M, Golyshin PN (2010) Systems approaches to microbial communities and their functioning. Curr Opin Biotechnol 21:532-538. doi:10.1016/j.copbio.2010.06.007

Russ L, Kartal B, Op den Camp HJ, Sollai M, Le Bruchec J, Caprais JC, Godfroy A, Sinninghe Damste JS, Jetten MS (2013) Presence and diversity of anammox bacteria in cold hydrocarbon-rich seeps and hydrothermal vent sediments of the Guaymas Basin. Front Microbiol 4:219. doi:10. 3389/fmicb.2013.00219

Sanapareddy N, Hamp TJ, Gonzalez LC, Hilger HA, Fodor AA, Clinton SM (2009) Molecular diversity of a North Carolina wastewater treatment plant as revealed by pyrosequencing. Appl Environ Microbiol 75:1688-1696. doi:10.1128/ AEM.01210-08

Schink B, Stams AJM (2013) Syntrophism among prokaryotes. In: Rosenberg E, DeLong E, Lory S, Stackebrandt E, Thompson F (eds) The prokaryotes. Springer, Berlin, pp 471-493. doi:10.1007/978-3-642-30123-0_59

Schluter A, Bekel T, Diaz NN, Dondrup M, Eichenlaub R, Gartemann KH, Krahn I, Krause L, Kromeke H, Kruse O, Mussgnug JH, Neuweger H, Niehaus K, Puhler A, Runte KJ, Szczepanowski R, Tauch A, Tilker A, Viehover P, Goesmann A (2008) The metagenome of a biogas-producing microbial community of a production-scale biogas plant fermenter analysed by the 454-pyrosequencing technology. J Biotechnol 136:77-90. doi:10.1016/j.jbiotec. 2008.05.008

Schneider T, Riedel K (2010) Environmental proteomics: analysis of structure and function of microbial communities. Proteomics 10:785-798. doi:10.1002/pmic. 200900450

Schuster M, Conrad R (1992) Metabolism of nitric oxide and nitrous oxide during nitrification and denitrification in soil at different incubation conditions. FEMS Microbiol Ecol 10:133-143. doi:10.1111/j.1574-6941.1992.tb00007.x

Seviour RJ, Kragelund C, Kong Y, Eales K, Nielsen JL, Nielsen PH (2008) Ecophysiology of the Actinobacteria in activated sludge systems. Antonie Van Leeuwenhoek 94:21-33. doi:10.1007/s10482-008-9226-2

Shi K, Zhou W, Zhao H, Zhang Y (2012) Performance of halophilic marine bacteria inocula on nutrient removal from hypersaline wastewater in an intermittently aerated biological filter. Bioresour Technol 113:280-287. doi:10. 1016/j.biortech.2012.01.117

Sieber JR, McInerney MJ, Gunsalus RP (2012) Genomic insights into syntrophy: the paradigm for anaerobic metabolic cooperation. Annu Rev Microbiol 66:429-452. doi:10.1146/annurev-micro-090110-102844

Silva CC, Jesus EC, Torres AP, Sousa MP, Santiago VM, Oliveira VM (2010) Investigation of bacterial diversity in membrane bioreactor and conventional activated sludge processes from petroleum refineries using phylogenetic and statistical approaches. J Microbiol Biotechnol 20:447-459

Silva CC, Hayden H, Sawbridge T, Mele P, Kruger RH, Rodrigues MV, Costa GG, Vidal RO, Sousa MP, Torres AP, Santiago VM, Oliveira VM (2012) Phylogenetic and functional diversity of metagenomic libraries of phenol degrading sludge from petroleum refinery wastewater treatment system. AMB Express 2:18. doi:10.1186/21910855-2-18

Simon C, Daniel R (2011) Metagenomic analyses: past and future trends. Appl Environ Microbiol 77:1153-1161. doi:10.1128/AEM.02345-10

Sorek R, Cossart P (2010) Prokaryotic transcriptomics: a new view on regulation, physiology and pathogenicity. Nat Rev Genet 11:9-16. doi:10.1038/nrg2695

Sorokin DY, Lucker S, Vejmelkova D, Kostrikina NA, Kleerebezem R, Rijpstra WI, Damste JS, Le Paslier D, Muyzer G, Wagner M, van Loosdrecht MC, Daims H (2012) Nitrification expanded: discovery, physiology and genomics of a nitrite-oxidizing bacterium from the phylum Chloroflexi. ISME J 6:2245-2256. doi:10.1038/ismej. 2012.70

Sowers KR, Baron SF, Ferry JG (1984) Methanosarcina acetivorans sp. nov., an acetotrophic methane-producing bacterium isolated from marine sediments. Appl Environ Microbiol 47:971-978

Speth DR, Hu B, Bosch N, Keltjens JT, Stunnenberg HG, Jetten MS (2012) Comparative genomics of two independently enriched "Candidatus Kuenenia Stuttgartiensis" anammox bacteria. Front Microbiol 3:307. doi:10.3389/fmicb. 2012.00307

Starkenburg SR, Chain PS, Sayavedra-Soto LA, Hauser L, Land ML, Larimer FW, Malfatti SA, Klotz MG, Bottomley PJ, Arp DJ, Hickey WJ (2006) Genome sequence of the chemolithoautotrophic nitrite-oxidizing bacterium Nitrobacter winogradskyi Nb-255. Appl Environ Microbiol 72(3):2050-2063

Stein LY, Arp DJ, Berube PM, Chain PS, Hauser L, Jetten MS, Klotz MG, Larimer FW, Norton JM, Op den Camp HJ, Shin M, Wei X (2007) Whole-genome analysis of the ammonia-oxidizing bacterium, Nitrosomonas eutropha C91: implications for niche adaptation. Environ Microbiol 9:2993-3007. doi:10.1111/j.1462-2920.2007.01409.x

Strous M, Pelletier E, Mangenot S, Rattei T, Lehner A, Taylor MW, Horn M, Daims H, Bartol-Mavel D, Wincker P, Barbe V, Fonknechten N, Vallenet D, Segurens B, Schenowitz-Truong C, Medigue C, Collingro A, Snel B, Dutilh BE, Op den Camp HJ, van der Drift C, Cirpus I, van de Pas-Schoonen KT, Harhangi HR, van Niftrik L, Schmid M, Keltjens J, van de Vossenberg J, Kartal B, Meier H, Frishman D, Huynen MA, Mewes HW, Weissenbach J, 
Jetten MS, Wagner M, Le Paslier D (2006) Deciphering the evolution and metabolism of an anammox bacterium from a community genome. Nature 440:790-794. doi:10.1038/ nature 04647

Suwa Y, Norton JM, Bollmann A, Klotz MG, Stein LY, Laanbroek HJ, Arp DJ, Goodwin LA, Chertkov O, Held B, Bruce D, Detter JC, Detter JC, Tapia R, Han CS (2011) Genome sequence of Nitrosomonas sp. strain AL212, an ammonia-oxidizing bacterium sensitive to high levels of ammonia. J Bacteriol 193:5047-5048. doi:10.1128/jb. 05521-11

Thomas GH, Zucker J, Macdonald SJ, Sorokin A, Goryanin I, Douglas AE (2009) A fragile metabolic network adapted for cooperation in the symbiotic bacterium Buchnera aphidicola. BMC Syst Biol 3:24. doi:10.1186/1752-05093-24

Tyson GW, Lo I, Baker BJ, Allen EE, Hugenholtz P, Banfield JF (2005) Genome-directed isolation of the key nitrogen fixer Leptospirillum ferrodiazotrophum sp. nov. from an acidophilic microbial community. Appl Environ Microbiol 71:6319-6324. doi:10.1128/AEM.71.10.6319-6324.2005

van de Vossenberg J, Woebken D, Maalcke WJ, Wessels HJ, Dutilh BE, Kartal B, Janssen-Megens EM, Roeselers G, Yan J, Speth D, Gloerich J, Geerts W, van der Biezen E, Pluk W, Francoijs KJ, Russ L, Lam P, Malfatti SA, Tringe SG, Haaijer SC, Op den Camp HJ, Stunnenberg HG, Amann R, Kuypers MM, Jetten MS (2013) The metagenome of the marine anammox bacterium 'Candidatus Scalindua profunda' illustrates the versatility of this globally important nitrogen cycle bacterium. Environ Microbiol 15:1275-1289. doi:10.1111/j.1462-2920.2012.02774. $\mathrm{x}$

van der Star WR, Abma WR, Blommers D, Mulder JW, Tokutomi T, Strous M, Picioreanu C, van Loosdrecht MC (2007) Startup of reactors for anoxic ammonium oxidation: experiences from the first full-scale anammox reactor in Rotterdam. Water Res 41:4149-4163. doi:10.1016/j. watres.2007.03.044

van der Star WR, Miclea AI, van Dongen UG, Muyzer G, Picioreanu C, van Loosdrecht MC (2008) The membrane bioreactor: a novel tool to grow anammox bacteria as free cells. Biotechnol Bioeng 101:286-294. doi:10.1002/bit. 21891

Wagner M, Smidt H, Loy A, Zhou J (2007) Unravelling microbial communities with DNA-microarrays: challenges and future directions. Microb Ecol 53:498-506. doi:10. 1007/s00248-006-9197-7

Walker CB, Redding-Johanson AM, Baidoo EE, Rajeev L, He Z, Hendrickson EL, Joachimiak MP, Stolyar S, Arkin AP, Leigh JA, Zhou J, Keasling JD, Mukhopadhyay A, Stahl DA (2012) Functional responses of methanogenic archaea to syntrophic growth. ISME J 6:2045-2055. doi:10.1038/ ismej. 2012.60

Wexler M, Richardson DJ, Bond PL (2009) Radiolabelled proteomics to determine differential functioning of Accumulibacter during the anaerobic and aerobic phases of a bioreactor operating for enhanced biological phosphorus removal. Environ Microbiol 11:3029-3044. doi:10.1111/j. 1462-2920.2009.02007.x

Wilmes P, Bond PL (2004) The application of two-dimensional polyacrylamide gel electrophoresis and downstream analyses to a mixed community of prokaryotic microorganisms. Environ Microbiol 6:911-920. doi:10.1111/j.14622920.2004.00687.x

Wilmes P, Bond PL (2006a) Metaproteomics: studying functional gene expression in microbial ecosystems. Trends Microbiol 14:92-97. doi:10.1016/j.tim.2005.12.006

Wilmes P, Bond PL (2006b) Towards exposure of elusive metabolic mixed-culture processes: the application of metaproteomic analyses to activated sludge. Water Sci Technol 54:217. doi:10.2166/wst.2006.390

Wilmes P, Andersson AF, Lefsrud MG, Wexler M, Shah M, Zhang B, Hettich RL, Bond PL, VerBerkmoes NC, Banfield JF (2008a) Community proteogenomics highlights microbial strain-variant protein expression within activated sludge performing enhanced biological phosphorus removal. ISME J 2:853-864. doi:10.1038/ismej.2008.38

Wilmes P, Wexler M, Bond PL (2008b) Metaproteomics provides functional insight into activated sludge wastewater treatment. PLoS ONE 3:e1778. doi:10.1371/journal.pone. 0001778

Wirth R, Kovacs E, Maroti G, Bagi Z, Rakhely G, Kovacs KL (2012) Characterization of a biogas-producing microbial community by short-read next generation DNA sequencing. Biotechnol Biofuels 5:41. doi:10.1186/1754-6834-541

Wooley JC, Godzik A, Friedberg I (2010) A primer on metagenomics. PLoS Comput Biol 6:e1000667. doi:10. 1371/journal.pcbi.1000667

Worm P, Koehorst JJ, Visser M, Sedano-Nunez VT, Schaap PJ, Plugge CM, Sousa DZ, Stams AJ (2014) A genomic view on syntrophic versus non-syntrophic lifestyle in anaerobic fatty acid degrading communities. Biochim Biophys Acta 1837:2004-2016. doi:10.1016/j.bbabio.2014.06.005

Wunderlin P, Mohn J, Joss A, Emmenegger L, Siegrist H (2012) Mechanisms of $\mathrm{N}_{2} \mathrm{O}$ production in biological wastewater treatment under nitrifying and denitrifying conditions. Water Res 46(4):1027-1037

Xia Q, Wang T, Hendrickson EL, Lie TJ, Hackett M, Leigh JA (2009) Quantitative proteomics of nutrient limitation in the hydrogenotrophic methanogen Methanococcus maripaludis. BMC Microbiol 9:149. doi:10.1186/1471-2180-9149

Yu K, Zhang T (2012) Metagenomic and metatranscriptomic analysis of microbial community structure and gene expression of activated sludge. PLoS ONE 7:e38183. doi:10.1371/journal.pone.0038183

Zhou J, He Q, Hemme CL, Mukhopadhyay A, Hillesland K, Zhou A, He Z, Van Nostrand JD, Hazen TC, Stahl DA, Wall JD, Arkin AP (2011) How sulphate-reducing microorganisms cope with stress: lessons from systems biology. Nat Rev Microbiol 9:452-466. doi:10.1038/ nrmicro2575 